\title{
A CRITICAL FRAME ANALYSIS OF THE VARIOUS PERSPECTIVES ON RECENT POLICY CHANGES TO REFUGEE HEALTH CARE IN CANADA
}

by

Brittney Emslie, BA, Wilfrid Laurier University, 2014

\author{
A Major Research Paper \\ Presented to Ryerson University \\ In partial fulfillment of the requirements for the degree of \\ Master of Arts \\ in the Program of \\ Immigration and Settlement Studies
}

Toronto, Ontario, Canada, 2015

(C) Brittney Emslie, 2015 


\section{AUTHOR'S DECLARATION}

I hereby declare that I am the sole author of this Major Research Paper. This is a true copy of the MRP, including any required final revisions, as accepted by my examiners.

I authorize Ryerson University to lend this MRP to other institutions or individuals for the purpose of scholarly research

I further authorize Ryerson University to reproduce this MRP by photocopying or by other means, in total or in part, at the request of other institutions or individuals for the purpose of scholarly research.

I understand that my MRP may be made electronically available to the public.

Brittney Renee Emslie 


\title{
A CRITICAL FRAME ANALYSIS OF THE VARIOUS PERSPECTIVES ON RECENT POLICY CHANGES TO REFUGEE HEALTH CARE IN CANADA
}

(C) Brittney Emslie, 2015

\author{
Master of Arts 2015 \\ Immigration and Settlement Studies \\ Ryerson University
}

\begin{abstract}
This paper explores the Federal Court of Appeal's (FCA) decision from July 4, 2014 that opposed the changes to the Interim Federal Health Program that traditionally provided a wide range of health care coverage for refugees and asylum seekers in Canada. Using a case-study approach, I will explore the various perspectives, outline policy implications and analyze what changes still need to be made from both federal and provincial governments. I will argue that Canada's current conservative government is using a neoliberal lens to justify their harsh decision-making regarding this issue and it is an approach that disregards fundamental human rights. However, it is clear that the humanitarian approach that is used by both the advocates as well as Justice MacTavish is the most popular amongst refugees, asylum seekers, academics, health care professionals and many Canadian citizens who oppose these changes. In my analysis, I use both critical frame and discourse analysis to unpack the various perspectives on this debate and explain how the stakeholders have framed their argument to offer a holistic view for understanding this unprecedented court ruling.
\end{abstract}

Key Words: Canada, Critical Discourse Analysis, Critical Frame Analysis, DCO, Health Care, Human Rights, Ideology, Interim Federal Health Program, Refugees, Social Construction 


\section{ACKNOWLEDGEMENTS}

I would like to thank my supervisor, Dr. Anver Saloojee for his constant support, encouragement and valuable guidance throughout the entirety of this project. I would also like to thank my second reader, Dr. Myer Siemiatycki for his important input to this paper. In addition, I would like to acknowledge the rest of the ISS faculty and fellow colleagues that I had the pleasure of meeting and working with over the past year. Lastly, a very special thank you to my friends, family and loving parents for their unwavering support during this project. 


\section{$\underline{\text { List of Acronyms }}$}

CARL - Canadian Association of Refugee Lawyers

CDA - Critical Discourse Analysis

CDRC - Canadian Doctors for Refugee Care

CHA - Canada Healthcare Association

DCO - Designated Country of Origin

EHCC - Expanded Health Care Coverage

FCA - Federal Court of Appeal's

HCC- Health Care Coverage

IFHP - Interim Federal Health Program

IRPA - Immigration and Refugee Protection Act

JFCY - Justice for Children and Youth

OIC- Order in Court

OTHP - Ontario Temporary Health Program

PHPS - Public Health and Public Safety Coverage 


\section{$\underline{\text { Table of Contents }}$}

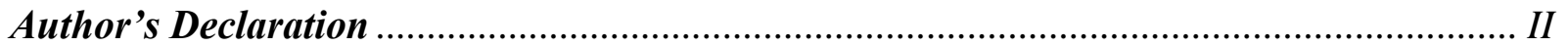

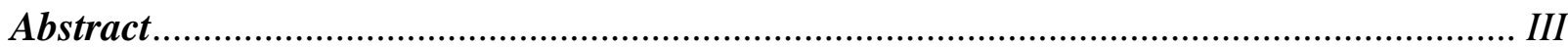

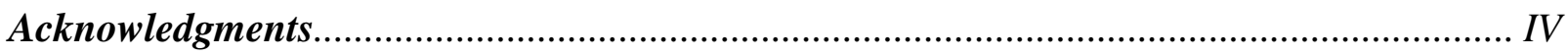

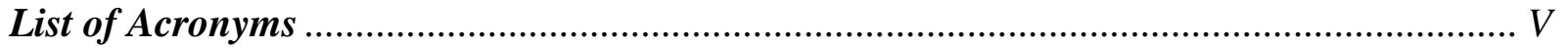

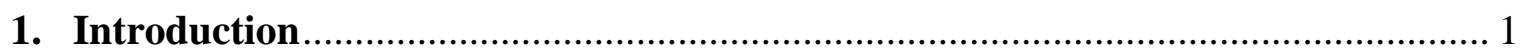

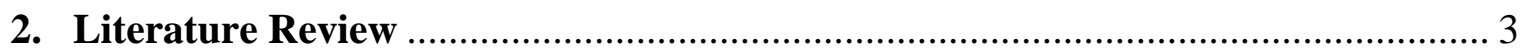

a. Policy: Interim Federal Health Program ............................................... 4

b. Developments in the Provinces.................................................................. 6

c. The Charter, Canada Health Act and Equality................................................ 8

d. Power, Ideology and the Social Construction of Refugees............................. 13

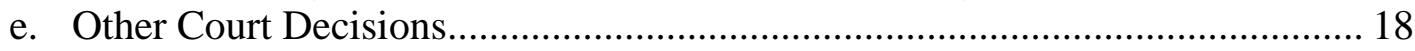

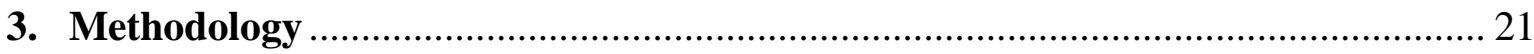

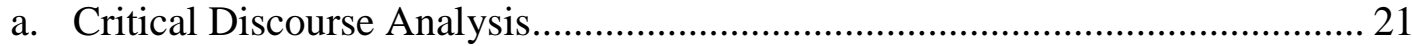

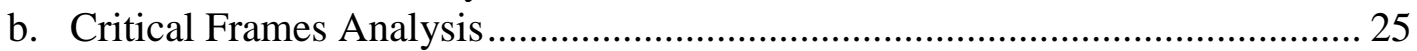

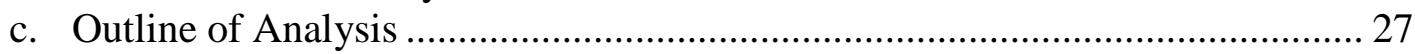

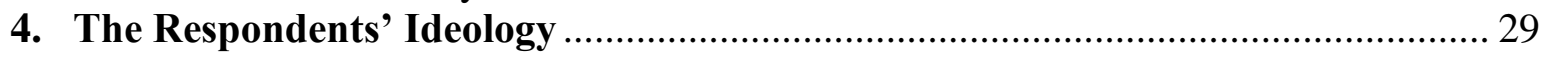

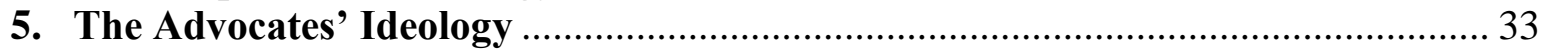

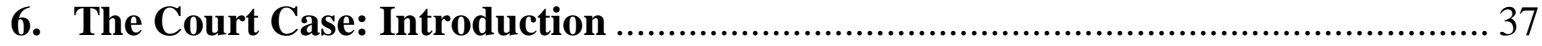

7. The Court Case Section One: The Applicants .................................................. 40

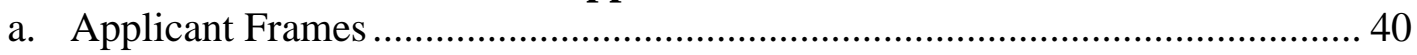

b. Applicant Frame Types ........................................................................ 51

8. The Court Case Section Two: The Respondents............................................ 54

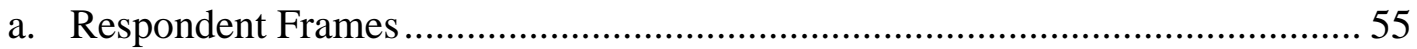

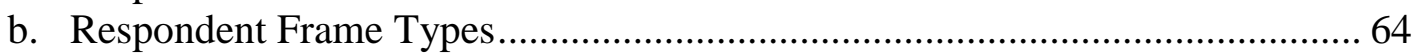

9. The Court Case Section Three: The Federal Court of Appeal's ............................ 66

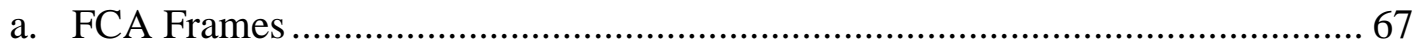

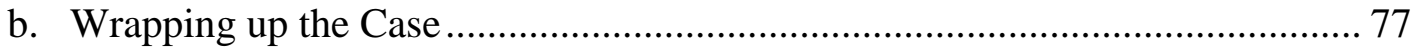

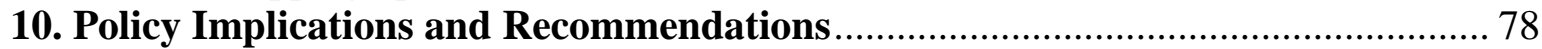

a. Recommendations with Respect to the Federal Government ......................... 79

b. Recommendations with Respect to Provincial Governments .......................... 80

c. Joint Federal and Provincial Recommendations ........................................... 82

d. Closing Thoughts on Policy Recommendations ........................................... 84

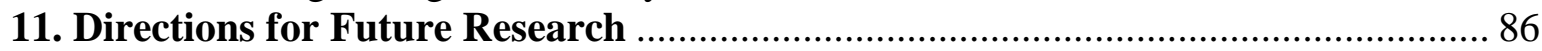

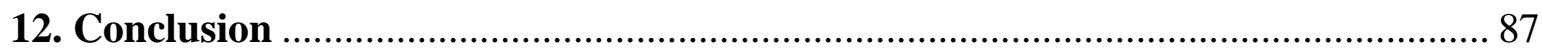

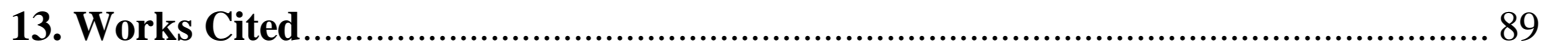




\section{Introduction}

Refugees consist of approximately 9\% of Canada's immigration quota each year (Hilliard December, 2014) out of the country's approximately 250000 new migrants (CIC Archives October 28, 2013). The country has signed many international conventions that are in place to ensure that refugees and asylum seekers are protected including the Convention Relating to the Status of Refugees in 1969, and the Convention on the Rights of the Child in 1990

(UNHCR:CRSR/CRC). This means that Canada has a commitment to uphold the rights laid out in the conventions to which it is a signatory. Access to health care and being in good health is necessary for refugees to achieve their full social and economic potential in their host country (Beiser 31). Evidence from both international and Canadian studies demonstrates that in comparison with other immigrant groups, in general refugees have poorer health as a result of difficulties with displacement and resettlement. The vulnerability that people feel during the migration process can be as a result of a significant increase in stress due to a decreased social safety net (Hansson et al. 112). Moving to another country, especially in a situation where an individual or family is forced to leave means that they are leaving behind supports that they had their entire life and are going somewhere completely new to start over again. Many refugees experience civil war, genocide, physical or psychological torture, family separation, and generally do not have access to health care prior to arriving in Canada (Marwah 4). These effects, which have now been exacerbated by the recent changes to the Interim Federal Health Program lead to even worse physical and psychological health conditions for refugees in Canada (Marwah 4).

The goal of this paper is to explore the Federal Court of Appeal's (FCA) decision from July 4, 2014 that opposed the changes to the Interim Federal Health Program (IFHP) that 
traditionally provided a wide range of health care coverage for refugees and asylum seekers in Canada. Using the FCA decision as a case study will allow me to illustrate, identify, and tease out issues of equality, accessibility, the social construction of refugees, and ideology that are apparent in the stakeholders' arguments on the debate about refugee health care. This case study is a platform that will allow me to explore numerous questions regarding these four themes and it will illuminate a huge shift in public policy. It will also allow me to question the government's approach to public policy, explain the role of the courts in Canada and illustrate a Charter challenge by stakeholders. Through this approach, I will explore the various perspectives, outline policy implications and analyze what changes still need to be made by both federal and provincial governments. It is extremely important to understand that while the FCA ruling is not final or binding as the decision is currently being appealed by the federal government, Honourable Madame Justice MacTavish's decision is still seminal because the arguments that will be analyzed, contextualized and framed from within the case are similar to the arguments that will be presented to the Supreme Court of Canada should the Court decide to hear the case.

A thorough analysis of the FCA document as well as popular discourses in the form of speeches, organizational statements, the Citizenship and Immigration Canada (CIC) website, media outlets and policy relevant texts will convey the dominant frames that emerge from each perspective. I argue that understanding the different frames and ideologies behind each argument is seminal to understanding the refugee health care debate, which at its heart lays issues of injustice, and threats to the human rights and human dignity of an already vulnerable and disadvantaged group. I will argue that Canada's current conservative government is using a neoliberal lens to justify their harsh decision-making regarding this issue and it is an approach that disregards fundamental human rights. However, it is clear that the humanitarian approach 
that is used by both the advocates as well as Justice MacTavish is the most popular amongst refugees, asylum seekers, academics, health care professionals and many Canadian citizens who oppose these changes. This approach is in line with Canadian values of human dignity, equality and fairness. I intend to critically engage with the themes of power, equality, and the ideological underpinnings that are evident throughout much of the discourse that has been examined to offer a holistic view for understanding this unprecedented court ruling.

The paper is organized as follows. I begin by providing a thorough literature review that provides the context and background to understanding health care and refugees in Canada. This section will consist of an analysis of relevant policy, the Canadian Constitution, examining literature on the social construction of refugees, international conventions, and lastly providing a brief look at similar court decisions. Following the literature review, I explain the methodology that I have chosen for this paper and describe how critical discourse and critical frame analysis will allow me to unpack the various perspectives on this issue. The main body of the paper will be divided into three sections, each of which looks at the discourse of a particular stakeholder-, one on refugee advocates, one on the federal government, and one explaining how the FCA came to their decision. All three sections will be examined through the lens of frames (critical frame analysis) which along with discourse analysis have proved to be very useful analytical and methodological tools. This eclectic methodology has allowed me to pull out themes that emerge as well as unpack the ideological underpinnings that lie beneath the various perspectives. Following the main body and analysis will be a discussion of my findings, as well as policy implications, recommendations and a conclusion. 


\section{Literature Review}

Before getting into the heart of the debate about the IFHP and unpacking Justice MacTavish's decision, it is important to provide some context as a way of grounding the debate. Therefore, before the main body of the paper I will provide a literature review that will be split up into four sections. The first section will provide a background on refugees and the recent health care policy changes in Canada. The second section will look at the Canadian Charter of Rights and Freedoms, the Canada Health Act, the Convention Relating to the Status of Refugees, the Convention on the Rights of the Child and issues of equality and accessibility as all of these are directly or indirectly referred to in the court case. The third section will look at the literature on the social construction of refugees, as this plays into the way refugees are constructed by both the government and advocates in the case. In addition, it will look at ideas of power and ideology to understand the ideological underpinnings behind the opposing sides. Finally, the last section will briefly look at the significance of similar court decisions to the one in this case study.

\section{A) Policy: Interim Federal Health Program}

The federal government established the IFHP in 1957, and it has been delivered by Citizenship and Immigration Canada (CIC) since 1995 (Canadian Healthcare Association (CHA) 3). The IFHP was used to help newly arrived refugees, refugee claimants, and their dependents pay for medical services after arriving in Canada temporarily if they have no provincial coverage or health insurance plan (CHA 3). The policy was introduced on the basis of humanitarian grounds so that eligible refugees could have:

access to essential and emergency medical/pharmacy/optical/dental services that will contribute to optimal health outcomes in a fair, equitable and cost effective manner, including immunizations and other preventative medical care, essential 
prescription medications, vision tests, non-emergency dental care, some elective surgery, prenatal and obstetrical care (CHA 3).

Before June 2012, the program provided temporary coverage to refugee claimants, resettled refugees, and protected persons and allowed them, regardless of their status, to access the health care services that they needed while in the process of filing claims (Marwah 3).

Changes to the Canadian IFHP coincide with policy reforms on immigration that fall under Bill C-31. This bill led to the creation of the Designated Country of Origin ${ }^{1}$ (DCO) list, which designates countries on the list safe because they do not normally produce refugees and supposedly respect human rights, therefore limiting access to services in Canada for refugee claimants from these countries (Marwah 1). The categories of health care coverage under the new IFHP are Expanded Health Care Coverage, Health Care Coverage, and Public Health or Public Safety Health Care Coverage. There are numerous factors involved that determine what tier of coverage a person has. These include their place in the refugee determination process, whether or not they are from a DCO, their current status if not a claimant (permanent resident, victim of trafficking etc.), if they are being detained and whether or not they are federally funded (MacTavish 21). The Expanded Health Care Coverage (EHCC) is similar to the level of IFHP benefits that were provided before the changes and pays for hospitals, physicians, nurses, ambulance services, supplemental services and prescription medications, vision benefits and emergency dental services (MacTavish 22). Though this tier of coverage seems beneficial, "only $14 \%$ of all IFHP beneficiaries now receive EHCC benefits" (MacTavish 23) which includes

\footnotetext{
${ }^{1} \mathrm{CIC}$ says that "the ability to designate such countries and accelerate the processing of refugee claimants from these countries provides the government with a tool to respond to spikes in claims from countries that do not normally produce refugees. Refugee claimants from DCOs [will] have their claims processed faster. This [will] ensure that people in need get protection fast, while those with unfounded claims are sent home quickly through expedited processing" (CIC Backgrounder- DCO).
} 
some privately-sponsored refugees, most government-assisted refugees, victims of human trafficking and some individuals admitted into Canada under humanitarian and compassionate grounds (MacTavish 23).

The federal government claims that the Health Care Coverage (HCC) tier is similar to the coverage that working Canadians receive through provincial insurance plans. Though beneficiaries of this tier receive coverage for hospital services, nurses, physicians, diagnostic and ambulance services, "these services and products are only covered if they are of an urgent or essential nature" (MacTavish 23). Recipients of this tier include non-DCO claimants, privately sponsored refugees and those who claimed refugee status before December 15, 2012. This tier accounts for $62 \%$ of IFHP beneficiaries (MacTavish 24). Lastly, Public Health and Public Safety (PHPS) coverage "only insures those health care services and products that are necessary or required to diagnose, prevent or treat a disease posing a risk to public health, or to diagnose or treat a condition of public safety concern" (MacTavish 25). Those entitled to PHPS coverage include refugee claimants from DCO countries filed after December 15, 2012, failed claimants, and those under investigation whose claims are suspended, accounting for approximately $24 \%$ of IFHP beneficiaries (MacTavish 25). Overall, the main goal of the changes was to ensure that coverage be limited to urgent or essential health services, to end coverage of supplemental benefits, to end coverage to rejected refugee claimants, to limit coverage of refugees from DCOs, and end coverage for Pre-Removal Risk Assessment ${ }^{2}$ applicants for those who have not applied for refugee status (Marwah 1). Therefore, unless health issues are of an urgent or essential nature, or posing a risk to public health and public safety, approximately $86 \%$ of refugees and refugee claimants in Canada do not have adequate access to health care under the new IFHP.

\footnotetext{
${ }^{2}$ According to CIC, "the Immigration and Refugee Protection Act provides that, with certain exceptions, persons in Canada may, in accordance with the Regulations, apply for protection if they are subject to a removal order that is in force. This is called a pre-removal risk assessment" (CIC- PRRA 2013)
} 


\section{B) Developments in the Provinces}

In early 2014, Ontario hosted "around 48900 refugee claimants, which is about $55 \%$ of the Canadian total"' (Glauser 70), yet Ottawa still feels adamant that it will not reconsider cuts to the IFHP, claiming that provincial governments are responsible for paying for health care (Glauser 70). On January 1, 2014 the Ontario Temporary Health Program (OTHP) was launched to assist refugee claimants who were not eligible to receive health care as a result of the changes to the IFHP. Through this policy, refugees from DCOs are able to access primary care and urgent services. All refugee claimants now have access to the equivalent of IFHP coverage, however to be eligible for OTHP they have a three month waiting period that does not start until the day that their application is accepted by CIC (Marwah 14). The exception to this waiting period would be children under 18, women requiring prenatal care, and people in life-threatening conditions (Marwah 14). A founding member of the Canadian Doctors for Refugee Care, Dr. Philip Berger “commended Ontario's decision as ethical and responsible, while calling the federal government the most hostile and vicious government to refugees and immigrants since the Second World War" (Glauser 70).

The province of Quebec “provides full medical, diagnostic and hospital coverage for failed claimants and DCO claimants with their Public Safety Health Care Coverage. This means that in Quebec, all refugee claimants have exactly the same access to health care, irrespective of whether they have the IFHP or Public Safety Health Care Coverage" (Marwah 14). For problems with mental health, refugee claimants have access to free psychotherapy. That being said, health care professionals in Quebec have stated that even though Quebec's government has made these changes for refugees, "claimants still have problems accessing health care services because providers are often unaware of this current health care program" (Marwah 14). Thus, 
even the changes that are being implemented at the provincial level still need to be improved. Quebec's program is similar to the OTHP, however, there is no waiting period, where as in Ontario refugees have a three month wait to qualify.

Though refugees in Ontario and Quebec now have greater access to health care services, refugees in other provinces throughout the country are still suffering and unable to receive treatment. The provinces of Quebec, Ontario, Alberta, Saskatchewan, Nova Scotia, and Manitoba have begun to address the problem of the gap in health care for refugees. The other provinces and territories need to ensure that all categories of refugees and claimants are receiving the health care services that they need by expanding accessibility to their provincial health care programs (Barnes 11). Though these changes in the provinces are praised and recognized, they do not do enough to adequately address and remedy the situation at a national level, which is contrary to the Canada Health Act. The Act is Canada's federal health insurance legislation. It defines the national principles that regulate health insurance throughout Canada including public administration, portability, comprehensiveness, universality and accessibility (Madore 1).

\section{C) The Charter, Canada Health Act, and Equality}

The Canadian Constitution is the highest law of the land in Canada. The two main parts of this document are The Constitution Act 1867 and The Constitution Act 1982 (Parliament of Canada: "The Constitution"). The Charter of Rights and Freedoms is an important part of the Constitution that came into force April 17, 1982, and is constantly referenced throughout the paper. The Charter identifies core Canadian values, clearly recognizes human rights and freedoms, and states that these rights should be enforced (Charter of Rights: "Inside the Charter"). Section 1 of the Charter: 
guarantees and limits the rights and freedoms set out. The rights and freedoms include fundamental freedoms, democratic rights, the right to live or work anywhere in Canada, the right to life, liberty and personal security, equality rights, the official languages of Canada, minority language education rights, multiculturalism, and aboriginal rights (Charter of Rights: "Inside the Charter").

As a way of protecting other rights and values that are important to Canadians, these rights are not absolute and can be limited (Charter of Rights: "Inside the Charter"). Furthermore, the Charter is used to regulate interactions between the different levels of government and individuals. It is "Canada's most important law because it can render invalid or inoperative any laws that are inconsistent with its provisions. The Charter has had a major impact on the promotion and protection of human rights in Canada. With regard to equality rights, it has led to the recognition and enforcement of the rights of a number of minority and disadvantaged groups" (Canadian Heritage: "The Charter") including refugees, which will be explained further when discussing relevant court cases below.

To continue the discussion on equality, provisions in the Charter "protect the individual's rights to belong to three types of communities simultaneously: the universal community of human beings, Canadian political communities, and individual identity communities" (Greschner 291). Greschner states that "equality law seeks to protect and promote belonging; to allow others into the fold, and to encourage and cement our bonds of community" (Greschner 293). When discussing equality and section 15 of the Charter, the notion of human dignity constantly surfaces because if a person experiences a section 15 violation, the effect is often demeaning to their dignity (Greschner 293). Even the Universal Declaration of Human Rights "begins with recognition of the inherent dignity and...the equal and inalienable rights of all members of the 
human family. For the drafters of international human rights conventions, and for some philosophers, human rights are based upon or derivative of human dignity" (Greschner 299). The discussion of equality and human dignity will be continued later in the section of the paper that explains Justice MacTavish's decision, as human dignity was a key factor in her ruling.

It is important to understand the Canada Health Act because it is integral to understanding the health care system of Canada and is repeatedly referred to in the court document. The Canada Health Act received Royal Assent on April 1, 1984 (Library of Parliament). It states that "the primary objective of Canadian health care policy is to protect, promote and restore the physical and mental well-being of residents of Canada and to facilitate reasonable access to health services without financial or other barriers" (Canada Health Act 5). This objective is why the Act is constantly referred to by advocate organizations and the FCA. Furthermore, the Canada Health Act is "Canada's federal health insurance legislation and defines the national principles that govern the Canadian health insurance system, namely, public administration, comprehensiveness, universality, portability, and accessibility. These principles reflect the underlying Canadian values of equity and solidarity" (Madore 1). The principles of comprehensiveness, universality and accessibility play into the refugee health care debate because advocates' believe that refugees deserve to have equal access to health care in Canada.

To reiterate, the Canada Health Act states that its primary objective is "to protect, promote and restore the physical and mental well-being of residents of Canada..." (Canada Health Act 5). Thus, the Act uses the term resident as opposed to citizen. Furthermore, this program was designed as a way of ensuring that all persons have access to hospital and physician services (Health Canada: Health Care System). The "Act defines insured persons as residents of a province. The Act further defines a resident as: 'a person lawfully entitled to be or to remain in 
Canada who makes his home and is ordinarily present in the province, but does not include a tourist, a transient or a visitor to the province"” (Health Canada: Health Care System). This means that residence in a Canadian province or territory is the requirement for insurance coverage. The ACT limits the waiting period to three months to establish if a person is eligible for insurance, and most provinces require residents to have been in the province for 183 days a year, and prove that they intend to go back to the province if they leave (Health Canada: Health Care System). Though refugee and asylum seekers are not considered in the ACT, they are still residents of our provinces, the same as new immigrants who are permanent residents or citizens; however they are still not qualifying for Canada's national health insurance plan and are left in vulnerable situations. Thus, the Canada Health Act "does not legislate concerning immigrant or refugee groups, nor does it provide health insurance for them" (MacTavish 100). While it is of my opinion that refugee claimants and asylum seekers are still residents of Canada's provinces, the $A C T$ does not mention them, which subsequently means that the group does not benefit from it. The responsibilities of Canada's health care system are shared between federal, provincial and territorial governments, however the provincial and territorial governments have more control over the administration and delivery of health services including setting priorities, administering budgets and managing resources (Madore 1). The Canada Health Act will be discussed further in the main body of the paper when breaking down the court document.

Lastly, this section will provide a brief look at the Convention Relating to the Status of Refugees and the Convention on the Rights of the Child, as these are constantly referred to throughout the paper and court document. The 1951 Convention Relating to the Status of Refugees created an international standard to evaluate persecution claims of asylum seekers (Gordon 646). This convention affirms that "human beings shall enjoy fundamental rights and 
freedoms without discrimination" (Gordon 645) as outlined as a main principle in the UDHR. To delve further into the convention, Article 16 guarantees refugees free access to courts and allows them the same treatment as nationals in legal matters. In addition, Article 31 does not allow host states to impose penalties on refugees as a result of illegal entry or presence in the country as long as refugees present themselves to the authorities without delay (Gordon 646). Furthermore, "Article 33 prohibits contracting states from expelling or returning a refugee in any manner whatsoever to the frontiers of territories where his life or freedom would be threatened" (Gordon 646). This convention was ratified by Canada on June 4, 1969; however the country has failed to uphold many of these clauses and as a result, refugees entering the country have suffered (Gordon 646). This convention will be referenced when discussing the argument of the refugee advocates in the main body of the paper.

The 1989 Convention on the Rights of the Child (CRC) recognizes that as a result of children's mental and physical immaturity, they need special care and safeguards, including legal protection. The convention "defines a child as every human being below the age of eighteen years...Perhaps the most important provision in the convention is Article 3 which created the 'best interest of the child' standard" (Gordon 647). This standard requires that in all matters that concern children, their best interest must be the primary consideration. The most important article of the CRC, in relation to this paper is Article 24, which says that "State Parties recognize the right of the child to the enjoyment of the highest attainable standard of health and to facilities for the treatment of illness and rehabilitation of health. State Parties shall strive to ensure that no child is deprived of his or her right to access to such health care services" (UNHCR: CRC). Canada became a signatory of the convention in May 1990, and ratified the convention December 1991, "however, the convention is not legally enforceable domestically unless enacted 
into domestic legislation" (Martin and Curran 450). Unfortunately, there are gaps and inconsistencies regarding the protection and care of refugee children in different provinces (Sadoway 380) and though their best interests should be a primary consideration, depending on their status some children are still left without adequate access to health care leaving them in extremely vulnerable situations. This is especially true for children from DCO countries, which as a result of these changes experience discriminatory treatment and have less access to social services than children from non-DCO countries. The differential treatment of children will be explained further when looking at the court document.

\section{D) Power, Ideology, and the Social Construction of Refugees}

The social construction of meaning can take place in the news media, think tanks, universities, groups in civil society and popular culture (Abu-Laban and Garber 521). The critical reading of news stories, editorials, government statements and opinion pieces can draw out themes about gender, race, ethnicity, current events and immigration (Abu-Laban and Garber 522). Dominant discourses, specifically the government's discourse about a topic or issue construct "the parameters of meaning within which certain terms are used in public discussions of particular issues" (Lacroix 150). Dominant or official discourses are the "set of views, arguments, explanations and policy suggestions advanced by those who speak for the state" (Karim 3). Karim states that "one of the primary features of a dominant discourse is its power to comment upon and interpret major issues and events; it maintains its superiority by being dynamic, continually co-opting and transmuting the words, images and symbols of other discursive modes" (Karim 4). The state is able to influence the dominant discourse that spreads throughout the country by consistently conveying the same message in the news media. For example, the government's negative discourse on refugee claimants and asylum seekers is now 
popular throughout Canada. While there are alternative discourses that oppose the dominant one, the dominant discourse is more popular and is able to convince large segments of the public that it is the best view or position on a policy issue because other alternative discourses are not as popular and well-known.

The state's own authority to act and construct meaning depends on the institutional, ideological and cultural context "within which the translation of "social reality; into policy problems or non-problems occurs... The construction of a public policy problem is informed by a view of the appropriate and potential role of the state in offering a solution" (Abu-Laban and Garber 524). Furthermore, though the dominant or national discourse can be influenced by alternative or oppositional discourses, overcoming these discourses is crucial in order to maintain its hegemonic status (Karim 4). Alternative or oppositional discourses can challenge the dominant ideologies and overall messages that are offered by dominant discourses (Karim 4). The mass media is a popular way to promote the dominant discourse, while alternative discourses tend to be disregarded (Karim 4) because the elites/government wants to maintain the status quo and their ideology. Through the use of media, state discourse is able to become the national discourse of Canada. The government uses frames to present information in an appealing way to the Canadian public, while purposely leaving out facts that might allow citizens to question their actions. Therefore, the state is able to convince large segments of the public to share its view by presenting information that is favorable to Canadian citizens, allowing Canadians to agree with the government's solutions or recommendations on certain issues. For example, when the government said that the cuts to the IFHP would increase tax savings and reduce 'bogus' refugee claims, the public saw this as favorable, while the negative health 
impacts that these changes would have on refugee claimants were left out of the dominant discourse.

The development of popular discourse on refugees and asylum seekers from deserving victims to 'bogus', 'queue jumpers' and 'criminals' can be understood by a shift in governmental rationalities away from humanitarianism (Pratt and Valverde 138). Furthermore, "while it is still true that humanitarian liberal ideals continue to wield some power...the discursive emphasis has shifted to the 'undeserving' (Pratt and Valverde 146). Through the use of the media, speeches and positional statements, the federal government has created a dominant national discourse that mainly sees refugees and asylum seekers as undeserving of Canada's generosity and as a burden on the country's welfare system, stemming from their overall neoliberal ideology that will be discussed in greater detail below.

It is important to understand the role of ideology when conducting critical frame analysis as it influences the way that frames are personified by speakers, constructed, and communicated (Ellis 25). When something is framed, the person or group who frames a situation purposely includes and omits certain phrases, words and images, making aspects of the situation more or less noticeable in an attempt to interpret, evaluate or recommend a specific solution for what is being described (Entman 52). In most situations, framing techniques are used help to indirectly promote that person or group's overall ideology. Discourse can be used as "a powerful tool in which these ideological intentions are conducted and maintained in the form of a frame" (Ellis $11)$.

After examining all of the literature, it is evident that there are two clear competing perspectives when looking at the refugee health care debate. One is a human rights based approach that is underlined with humanitarianism, while the other has an overall neoliberal 
ideology behind its justification. Within the policy context, ideology can be used to construct frames that are held by officials and policy makers (Ellis 10). In explaining a neoliberal ideology, Ellis states that these "policy frameworks privilege individualism and self-reliance, reductions in government spending on social programs and a shrinking of state involvement in the market economy to allow for free enterprise. Such ideological commitments, which have gained traction in Canada's political rationality, describe a position or set of beliefs yet also reveal a distribution of power justified by neoliberal aims" (Ellis 10). Thus, an examination of the federal government's neoliberal ideological underpinnings will help to explain their rationale in creating these health care changes and will be discussed in greater detail later in the paper.

To bring the discussion back to the idea of social construction, it can be defined as "the process through which information acquires collective meaning, whether it occurs in the news media and political discourse or in communicative arenas such as advertising or popular culture" (Abu-Laban and Garber 524). Power is often linked with social construction as it can be viewed as a struggle for the command of information to facilitate defining ideas to achieve an end (AbuLaban and Garber 524). Though framing will be described more thoroughly in the next section of the paper, it can briefly be described as a process that allows a researcher to understand how ideas that are expressed through discourse are able to impact public opinion (Entman 51). For example, the Canadian government uses public discourse to determine whether an event or situation should be seen as a problem or issue in Canadian society and uses the media to portray their message and ideology. This directly relates to social construction because if the government continuously uses discourse such as 'bogus' and 'undeserving', when discussing refugees, they are socially constructing them in a negative way that will resonate with much of Canadian society. 
When examining the framing and social construction of immigrants and refugees in Canada, the news media is a "significant arena of construction of definitions of both political facts and public policy problems. The process of social construction depends upon the creation of a widely accepted interpretive framework that deflects, denies, and distorts alternative constructions or definitions of social reality" (Abu-Laban and Garber 524). In Canada, as in most refugee hosting countries, the concept of asylum is associated in both the political and public imagination with a rise in immigration levels (Goodman and Speer 165). Once again, from the government's dominant discourse, asylum seekers have been described and constructed in terms such as 'bogus' or 'genuine', where bogus refugees are seen as undeserving of Canada's generous refugee determination system (Goodman and Speer 166). To be clear, when discussing different refugee categories, 'refugees' are people whose claims have been accepted and it has been determined that they do in fact fit the definition of a refugee. 'Refugee claimants' are those who are in the process of applying for refugee status or have applied and are waiting for their determination and 'asylum seekers' are those whose claims have not yet been evaluated (UNHCR: Asylum Seekers).

Goodman and Speer argue that "asylum seekers are a group of people who may be discriminated against, and dealt with unequally, through the way in which they are constructed in discourse. It is in this way that power can function through discourse" (Goodman and Speer 167). To continue their discussion on power, they argue that "when people engage in the morally oriented activities of describing, judging or making claims about others, their activities both reflect and compose moral reality. It is in this way that category use can be seen as doing interactional work that may constitute political action" (Goodman and Speer 167). For example, by categorizing asylum seekers into groups such as bogus and illegitimate, or genuine, legitimate 
and deserving, the dominant discourse is commenting on the moral status of asylum seekers (Goodman and Speer 167) rather than focusing on why they need protection in the first place. The way that refugees and asylum seekers are categorized and constructed in the dominant discourse can have political implications that result in negative attitudes and treatment towards them (Goodman and Speer 168). However, as previously discussed, the dominant discourse can be challenged by counter-dominant or oppositional discourses, as there are multiple conflicting voices and opinions in the public sphere that exist within the dialogical network where asylum is debated (Goodman and Speer 168).

Goodman and Speer conclude that "those who oppose asylum seeking [will] continue using this genuine/bogus classification, whereas those who support asylum seeking will need to attempt to move the debate away from this" (Goodman and Speer 179). This is precisely what the refugee advocates are trying to do in the court case, however, the dominant discourse that has ultimately dominated the dialogical network about asylum has more power than alternative discourses in influencing the Canadian public. Power "seems to be the capacity to articulate and to make those articulations not only 'stick' but become hegemonic and pervasive. In this sense, asylum seekers remain a weak group being acted upon by those with power" (Goodman and Speer 180). That being said, the advocates are trying hard to change this negative dominant discourse to one that sees refugees as deserving of fundamental human rights, human dignity, equality, and proper access to health care.

\section{E) Other Court Decisions}

When deconstructing this court decision, it is also important to look back and examine cases that somewhat relate or had similar outcomes. It is of course important to mention the case Canada v. Singh, which went to the Supreme Court of Canada as the refugee claimants in the 
case claimed a Section 7 charter violation since they were not able to have an oral determination hearing (Singh v Canada). This case is extremely significant because it brought forth the right to oral hearings for refugee claimants in Canada. That being said, the two cases that are perhaps more directly related to this case are Canada v. Ward and Canada v. Chan (Ward v Canada/Chan v Canada). They both deal with the issue of refugee rights under the Constitution and have a similar ruling to the one analyzed in this paper, in that the final decision for each was in the interest of refugees and dealt with issues of human rights and equality. The Ward case is important as context because this was the first time that the Supreme Court of Canada was involved with the interpretation of the definition of a Convention Refugee. ${ }^{3}$ Ward, a citizen of Ireland and the UK was a member of the Irish National Liberation Army (INLA). He was in charge of guarding innocent hostages, however, when he learned that they would be executed he secured their escape as he did not believe killing was acceptable to achieve political change (Ward $v$ Canada). He escaped from Ireland and the INLA because he feared for his life and claimed that the authorities in Ireland could not protect him (Shacter 724). He arrived in Canada in 1985 and claimed Convention Refugee status based on fear of persecution by the INLA (Ward $v$ Canada). The case eventually went to the Supreme Court, as the Parkdale Community Legal Services argued that the FCA ruling went against international law and the Charter (Shacter 724). This is because the FCA "required a) state complicity in persecution in certain circumstances and $b$ ) that the activities of a particular social group (one of the five possible grounds for claiming refugee status along with race, religion, nationality and political opinion)

\footnotetext{
${ }^{3}$ The Immigration and Refugee Board states that "a Convention Refugee is a person who by reason of a wellfounded fear of persecution for reasons of race, religion, nationality, membership in a particular social group or political opinion, a) is outside of their countries of nationality and is unable, or by reason of that fear, is unwilling to avail themselves of the protection of each of those countries, or b) not having a country of nationality, is outside their country of former habitual residence and is unable or, by reason of that fear, unwilling to return to that country" (IRB: Convention Refugee Definition).
} 
be perceived as a threat to the state" (Shacter 724). As a result of this violation of the Charter and international law, the FCA decision was appealed and being heard by the Supreme Court of Canada.

If the FCA decision had been final, in most cases vulnerable women and children would be denied Convention Refugee status "because they are generally not seen as a danger by agents of persecution" (Shacter 725). The Supreme Court "explicitly recognized women, children and sexual orientation as constituting the basis for particular social groups. In addition, for refugee status to be granted the Court required that claimants be credible and demonstrate a lack of state protection from the persecution feared, owing to membership in such a group. There is no need for claimants to show state complicity in such persecution" (Shacter 725). Shacter argues that "the Court clarified that the protection of basic human rights informed the interpretation of the elements of the definition of Convention refugee. Tribunals can no longer properly deny that women, for example, are a particular social group, or exclude "private persecution" (e.g., women fleeing domestic violence) from the scope of the definition of Convention refugee" (Shacter 725). Thus, this decision has been extremely significant in helping vulnerable refugees achieve Convention Refugee status. A Convention Refugee can be defined as a person that has a wellfounded fear of persecution as a result of their race, nationality, religion or political opinions that is outside of their country of origin and unable or unwilling to return to that country for fear of being persecuted (IRB: Convention Refugee Definition)

In the case of Chan $v$ Canada, Mr. Chan filed for refugee status in Canada because his wife gave birth to more than one child under China's one child policy. He refused to let himself or his wife undergo forced sterilization and left China (Shacter 725). Chan was afraid to return because of the harassment that his family endured when being left behind. He claimed he might 
be imprisoned, remain unemployed long-term, or be physically assaulted or murdered (Chan $v$ Canada). He left China in July 1990, two years after his second child was born and claimed Convention refugee status in Canada (Chan v Canada). The FCA ruled that if someone resists a valid state policy they cannot be considered a Convention Refugee and "any means used by a state, including a violation of a basic human right such as physical integrity and reproductive capacity, would be justified; anyone fleeing such treatment would be denied refugee status" (Shacter 725).

Originally, the Supreme Court denied the appeal; however, Mr. Justice La Forest "found that Mr. Chan's fear was objectively well-founded. In addition, he referred favorably to the Canadian Council for Refugee's factum and held that a law or policy of general application may violate basic human rights" (Shacter 725). Therefore, he claimed that forced sterilization can be seen as a form of persecution and a human rights violation. This case is significant because it highlights the protection of basic human rights and that "the end (i.e., a valid state policy) can never justify the means (i.e., a violation of such rights)" (Shacter 726). These cases are extremely important because they have laid the groundwork for future successful court rulings regarding the human rights of refugees and asylum seekers. They are similar to the case that will be analyzed in this paper as they are also challenging human rights violations. They both offer an interpretation of the Canadian constitution, and highlight the fact that refugees should be treated equally under international and domestic law. Both cases deal with state policies that violate rights and show that government policy can be challenged. The refugee health care debate is similar to these cases, however the human right in question is access to health care and the implications of this policy are disastrous for thousands of refugee claimants in Canada. 


\section{Methodology}

\section{A) Critical Discourse Analysis}

I plan to use a comprehensive eclectic approach that combines critical discourse analysis, critical frame analysis and an analytical framework that allows me to simultaneously understand how refugees are socially constructed and allows me to deconstruct the dominant discourse as expressed in official documents and statements. These will be examined throughout the paper. Before understanding what critical discourse analysis is, it is important to define what discourse analysis itself is. Hardy and Phillips define "a discourse as a system of texts that brings an object into being. Discourse is therefore the foundation of the process of social construction upon which social reality depends" (Hardy and Phillips 2). Rather than mirroring reality, discourse highlights certain situations, knowledges, social identities, and relations among people (Hardy and Phillips 2). Discourse occurs though mass media such as newspapers, movies, television, the internet and the radio which all allow for the production and distribution of different forms of text to a wide audience (Hardy and Phillips 6).

Critical discourse analysis (CDA) is performing analysis from a critical perspective, and focuses on concepts previously discussed such as power, ideology and the social construction of refugees. Critical discourse scholars generally use qualitative techniques, in addition to analyzing historical, social, and political contexts and therefore go beyond analyzing only the language being used (Baker et al. 273-274). When CDA is used to analyze social construction, analysts focus on how information can acquire collective meaning throughout society through use of the news and political discourse (Abu-Laban and Garber 524). Analysts look at how the media constructs some information as beneficial for society and other information, events and occurrences as problems that need to be dealt with. In addition, analysts delve into the ideology and justification behind why an issue has been constructed a certain way. CDA has been heavily 
influenced by the work of Foucault and has drawn upon Halliday's systemic-functional grammar linguistic theory that focuses on the function of language in the social structure (Hart et al. 189). $\mathrm{CDA}$ is seen as an instrument that can be used to examine social manipulation in society through the use of discourse (Hart et al. 191). CDA "is informed by social theory and views discursive and linguistic data as a social practice, both reflecting and producing ideologies in society" (Baker et al. 280). The analysis of text allows the researcher to learn if values in the text are common or absent (Bednarek and Caple 140). When performing CDA, techniques such as analyzing keywords, the frequency of words, and grammatical and semantic tags can be used (Bednarek and Caple 141).

In CDA, metaphors can be used to form a certain view of reality where they privilege a certain understanding of reality over others (Hart 91). Discourse itself is both produced and interpreted with human interaction and contributes to knowledge construction about processes, identities and objects (Hart 91). Therefore, the use of discourse can be seen as a way of achieving certain strategies or outcomes (Hart 99). CDA researchers analyze relationships of power and control, dominance, and discrimination in society, specifically looking at how these relationships unfold through discursive practices (Baker et al. 280). This is precisely what I will be doing when analyzing ideas of power, ideology and social construction through government and advocate discourse.

When utilizing CDA, it is important to understand relations of power, including how a person has control and access to public spheres that can influence discourses such as scholars, politicians, and journalists, all of whom can reproduce dominant ideologies within society (Baker et al. 280). Prejudices in society are socially constructed through public discourse by those that have control over such discourse (Baker et al. 280). Therefore, critical discourse analysts "would 
not only be interested in accounting for what linguistic elements and processes exist in a text or set of texts, but would also need to explain why and under what circumstances and consequences the producers of the text have made specific linguistic choices among several other options that a given language may provide" (Baker et al. 281). This means that analysts need to looks at what is present as well as what is missing from the data examined.

It is also important to understand discourse in relation to dominance, which can be seen as an exercise of power by elites and institutions resulting in social, cultural, political, gender, and ethnic inequality (Teun and Dijk 249-250). Critical discourse analysts try to unpack what structures in society contribute to reinforcing the reproduction of dominance. CDA's focus on relationships of power, dominance, and inequality shows that it is motivated by social issues that can be better understood through the analysis of discourse. The ultimate aim of CDA is affecting social change in society through critical understanding (Teun and Dijk 252). This means that "their critical targets are the power elites that enact, sustain, legitimate, condone or ignore social inequality and injustice. That is, one of the criteria of their work is solidarity with those who need it most" (Teun and Dijk 252). CDA offers a political critique of those in society that are responsible for various inequalities. The success of critical discourse analysts is measured by its effectiveness and whether or not it contributes to change (Teun and Dijk 253). Thus, my analysis will focus on critiquing the power of the federal government and highlighting inequality that refugees and asylum seekers are forced to deal with as a result.

CDA is also interested in and examines breaches of rules and laws as well as breaches of principles of democracy, justice, and equality by those in power (Teun and Dijk 255). The use of discourse can define, redefine, create, and recreate different attitudes and beliefs in society (KhosraviNik 3). The use of discrimination in discourse can be very apparent as discourse may 
establish social and political practices that disadvantage some groups. Public discourse can be used as a way of spreading prejudiced ideologies; however, it can also be used to recreate attitudes and knowledges in society (KhosraviNik 3). The advocates are using discourse to try and change or recreate the current negative attitude towards refugees in Canada. CDA has been used as a lens from which to analyze the overall discourse that is used from the various stakeholders in this debate. This lens allows me to unpack the various frames and ideologies that have emerged from the competing perspectives. Thus, while framing is the way that one is able to view information, discourse analysis is a mechanism to unpack the various arguments. The paper will now briefly explain critical frame analysis (CFA) before moving on to the main analysis.

\section{B) Critical Frame Analysis}

The concept of framing has been largely derived from the work of Goffman (1974) who claims that "frames denote 'schemata of interpretation' that enable individuals to locate, perceive, identify and label occurrences within their life space and the world at large" (Benford and Snow 614). Framing is a continuously ongoing process that is affected by various elements of the social, cultural, political, and economic context that they are surrounded by (Benford and Snow 614). There is lack of a framing theory that explains how frames are embedded in text or how frames influence peoples thinking; however, analyzing frames helps explain how ideas expressed through discourse can inform human consciousness (Entman 51-52). When something is framed, by a politician, journalist etc. they choose a few aspects of a perceived reality and make them more noticeable than others in a text as a way of promoting a problem, interpretation, evaluation, or recommendation for what is being described (Entman 52). Furthermore, Entman argues that "text contains frames, which are manifested by the presence or absence of certain key 
words, stock phrases, stereotyped images, sources of information, and sentences that provide thematically reinforcing clusters of facts or judgments" (Entman 52).

The word salience means take a piece of a story and making it more noticeable and memorable to those looking at a text. This means that when salience increases, people will intake the specific information highlighted and will remember it (Entman 53) at the same time not understanding the entire picture or other side of the story. The use of frames in public discourse often determines if and how people understand a problem, and what they choose to do about it. Furthermore, "the notion of framing thus implies that the frame has a common effect on large portions of the receiving audience, though it is not likely to have universal effect on all...frames select and call attention to particular aspects of the reality described, which logically means that frames simultaneously direct attention away from other aspects" (Entman 54). When examining frames it is important to look at what they do not include, what is missing in definitions and evaluations, and what remedy is recommended for a problem because people's responses to problems will be influenced by what they know and what they do not know about a situation (Entman 54).

Frames are not self-evident, that is, they must be constructed or deconstructed in order to study them. To do this an analyst "must infer interpretations about belief and meaning and implications or action to deal with coping and facing. In constructing a frame, however, we encounter inherent possibilities for ambiguity, because the same beliefs and meanings can be consistent with different courses of action and attitudes toward truth" (Rein and Schon 90). Thus, for my analysis I analyzed and deconstructed metaphors, recurring words, patterns and themes that kept coming up in the various arguments in the refugee health care debate. In doing so, I constructed various frames and found frame types to help explain them. The types that will be 
explained in the analysis below are Risk and Information Frames, Collective Action Frames, Issue Frames, and Identity and Characterization Frames. These various frame types are used to help explain how and why certain frames have been strategically used by both the applicants and the respondents to further their arguments and appeal to the Canadian public with their side of the debate.

My methodological approach combines unpacking the social construction of refugees with the use of critical discourse and critical frame analysis as a way of understanding the refugee health care debate in Canada. CDA has allowed me to delve into the ideological underpinnings that lie beneath the various perspectives; understand relationships of power, dominance, and discrimination in Canadian society and illustrate breaches of democracy, justice and equality (Teun and Dijk 255). Along with CDA, frame analysis has allowed me to understand how frames influence people's thinking and inform human consciousness, as well as look at what is present and what is absent from sources of information. This is important because a person's response to a situation is influenced by what they know about it (Entman 51-52).The social construction of refugees is the piece of my methodological approach that brings everything together, as it has influenced the public perception of refugees in Canada and has mainly associated refugees with negativity. Thus, the government has been able to maintain the dominant discourse about refugees by using words such as 'bogus', 'que jumper', and 'undeserving' of Canada's generous determination system. They have framed the refugee health care debate in a way that makes it seem like they were receiving more coverage than Canadian citizens through the IFHP and claim that these changes were necessary to ensure fairness for Canadians. This allowed them to receive public support on these changes without sharing all of the facts and implications as a result of these changes. Thus, the debate on refugee health care is 
largely influenced by the government's social construction of refugees through the use of the news media and political statements.

\section{C) Outline of the Analysis}

I intend to use critical discourse and critical frame analysis throughout the main body and analysis of this paper to better understand the discourse surrounding this issue. I am going to break the main body down into three sections. The first section will be looking at the argument of health care professionals and refugee advocates, the second section will be looking at the government's argument and the third section will be analyzing the justification for Justice MacTavish's ruling explaining why the IFHP cuts are unconstitutional and a form of cruel and unusual treatment. The core of my analysis for these three sections will come from deconstructing the FCA document that clearly lays out the competing perspectives. In addition to analyzing this document, for the first section that is looking at health care professionals and refugee advocates, I plan to look at statements from the Canadian Healthcare Association, Canadian Nurses Association, Canadian Pharmacists Association, Canadian Doctors for Refugee Care, and the Canadian Association for Refugee Lawyers. These organizations have been directly affected by these changes, they are directly dealing with refugees that have been impacted, and some of these organizations were directly involved in the court case in July 2014. I will examine policy and organizational statements that relate to the cuts to health care to get a deeper understanding of their perspectives in the refugee health care debate.

In delving further into the government's argument, I am planning to examine sections of the CIC website, speeches, policy relevant texts and media outlets for statements that have been made directly on these sites or to the news media about changes to health care for refugees. I believe that these sources are the most efficient to analyze government discourse about refugees 
and health care and how they have framed their argument. When looking at documents for these two sections, I will be referring to a designated time period, from June 2012 to July 2014, as this is the period from when the IHFP was changed to when the FCA decision was made. Lastly, the third section of the main body that focuses on the decision of the FCA will look specifically at the court document to explain how Justice MacTavish reached her decision. Through the use of critical frame analysis I have pulled out themes and patterns that emerge in Justice MacTavish's rationale, as well as in the arguments of the advocates and the government. Before I describe the various frames that I have constructed through my analysis, I will provide a thorough background of the ideological underpinnings of both sides of this debate.

\section{The Respondents' Ideology}

The Canadian government believes that the reform to the IFHP was necessary as a way of ensuring greater fairness for Canadians, as the IFHP provided supplemental benefits ${ }^{4}$ not covered by the average Canadian's provincial and territorial insurance programs (CHA 4). The federal government claims that refugees should not be eligible to receive better health care and benefits than Canadian citizens. Former Immigration Minister Jason Kenney said that "Canadians are a very generous people and Canada has a generous immigration system. However, we do not want to ask Canadians to pay for benefits for protected persons and refugee claimants that are more generous than what they are entitled to themselves" (CHA 4). Kenny said this because the supplemental benefits that were provided under the previous IFHP included prescribed medications, devices to assist mobility, home and long term care, psychological counselling and post-arrival health assessments, benefits that not all Canadian citizens are entitled to (CHA 3). The government also defends their decision by saying that these new changes can contain costs.

\footnotetext{
${ }^{4}$ These supplemental benefits included "prescribed medications and other pharmacy products; limited dental and vision care prosthetics and devices to assist mobility; and home care and long term care; psychological counselling provided by a registered clinical psychologist; and post-arrival health assessments" (CHA 3).
} 
CIC "says that the IFHP costs $\$ 84$ million annually and that the changes that took effect June 30, 2012 are anticipated to save approximately $\$ 20$ million per year over the next five years" (CHA 5). As a result, the government believes that these amendments will ultimately allow them to better protect public health as well as public safety, defend the integrity of Canada's immigration system, and ensure tax dollars are spent wisely (Marwah 11) to benefit Canadian citizens.

While it is difficult to find scholars who would agree with the government's decision, the motivation to single out refugees and limit the rights that they are entitled to can be understood using a neoliberal framework that says we should make economically sound decisions with regards to policy making. The neoliberal worldview justifies the current trend of weakening social services, privatizing, and reforming health care systems (McGregor 82). The development of health care policy is "comprised of government decisions affecting cost, delivery, quality, accessibility, and evaluation of programs...designed to enhance the physical well-being of all members of the population" (McGregor 82). Officials and policy makers are pursuing a neoliberal agenda and hold to the view that private markets are both more cost-effective and consumer-friendly. As a result, there have been cuts to government spending on health care (McGregor 83). This is precisely what has happened in Canada when the federal government amended the IFHP.

Wrenn argues that a person is seen as 'defective' if they lack the means or ambition to achieve financial success (Wrenn 503). In this case, the 'defective' person would be considered the refugee. Since many are not in a financially secure position when they first enter Canada, they lack the means to be able to finance their own health care requirements. Wrenn also includes the importance of social identity, and says that identity "is other-assigned by the surrounding institutional context that may be based on biological characteristics, such as race or 
gender, and social attributes, such as income class or identifications with socially constructed meanings" (Wrenn 504). This is especially true for refugees, as their social identity has already been constructed and described for them through dominant discourse before they even enter Canada.

McGregor argues that "advocates of neoliberalism believe in pressuring the poorest people in a society to find their own solutions to their lack of health care, education, and social security" (McGregor 84). Neoliberals feel that there should be no preferential treatment, all members of society should be treated equally (McGregor 85). Therefore, based on this argument allowing refugees to have special access to health services would not be fair. In discussing the free market, McGregor argues that consumer spending is said to advance society's well-being by stimulating the economy. She continues, "the neoliberal assumption that private ownership of formerly public assets generates economic growth is a driving force behind market-oriented health care reform" (McGregor 86). This ideology concludes that if people are able to pay for health care, they are worthy of being served because in doing so they are contributing to economic growth (McGregor 86). In sum, a neoliberal view holds that not everyone is entitled to health care, only those who can afford it should have access to it, and those who cannot purchase health care (refugees) are left behind (McGregor 87).

It has been almost three years since the government reformed Canada's asylum system in an attempt to provide faster and fairer protection to those in need. Under the new system, 'genuine' refugees are getting the protection they need sooner and failed asylum claimants are being removed more quickly. Since the government reformed Canada's refugee determination system in 2012 by reducing processing times and speeding up removals, they claim that "the overall reduction in asylum claims has already resulted in greater-than anticipated savings to 
Canadian taxpayers of more than $\$ 600$ million in provincial and federal government welfare, education and health-care costs within the first fiscal year of the new system. Overall savings are projected to be more than $\$ 1.6$ billion over five years" (Alexander 2014). When Chris Alexander, the current Immigration Minister commented on the changes to Canada's asylum system, he was quoted stating that:

we're now able to provide faster protection to genuine refugees, enabling them to start their new lives in Canada. We're also able to remove from Canada more quickly failed asylum claimants whose claims are deemed unfounded by the independent and quasi-judicial Immigration and Refugee Board (IRB). This in turn reduces costs for Canadian taxpayers through savings to provincial and federal governments for welfare, education and health care costs. So because this system is no longer bogged down by claimants simply looking to take advantage of our generosity, Canada is able to offer protection to these genuine refugees much more quickly (Alexander January 22, 2014).

In addition, former Immigration Minister Jason Kenney stated that "our government has a plan for a faster, more flexible, responsive and secure immigration system that will better meet Canada's economic needs while continuing to uphold our humanitarian commitments... with our changes, immigrants will see their lives improve, and Canadians will see the economy grow" (CIC Archives August 24, 2012).

In continuing to justify their neoliberal ideology, the government claims that the IFHP's sole purpose is not just to focus on medical illnesses and treatment. They say that we need to look at the changes to the IFHP within the context of the Canada's new refugee determination system and what the government is trying to implement more broadly. Therefore, the health cuts 
do not actually account for whether or not people are benefitting from the program, rather they relate to the government's overall goals in the area of refugee law in Canada (MacTavish 215216). Justice MacTavish confirms this by stating that "the Supreme Court has reminded us of the importance of looking beyond the impugned government action in a section 15 charter analysis,

and the need to examine the larger social, political and legal context of the legislative distinction in issue" (MacTavish 176). This larger analysis is precisely what is being examined and explained throughout this paper. The paper will now look at the ideological underpinnings that are behind the advocates' argument.

\section{The Advocates' Ideology}

Advocates of providing health care to refugees are proponents of a human rights based approach to social policy. They advocate for the human rights of refugees both internationally and domestically, as can be seen through their discourse and arguments in the court case. In opposition to the government reforms of the IFHP, the Canadian Healthcare Association (CHA) claims that the changes may in the long run lead to extra health costs if health conditions are not managed and treated. They believe that the changes will not be in the best interests of creating a healthy Canada. Further they argue it is unfair to impose these changes onto refugees, an already extremely vulnerable group in society (CHA 2). Researchers from the University of Ottawa have come to the realization that the IFHP did not provide enough health care coverage even before the reforms, and recommended coming up with a more comprehensive program to make up for its shortcomings (CHA 7).

Using a humanitarian rights based approach, refugee advocates and scholars effectively defend the argument that refugees should have access to proper health care by claiming that Canada is a signatory of the 1951 United Nations Convention Relating to the Status of Refugees, 
as well as the Constitution of the World Health Organization and the Universal Declaration of Human Rights (Arya et al. 1875). Canada accepts approximately 25000 refugees per year and should therefore guarantee refugees in the country their universal right to a high standard of health care (Arya et al. 1875). Furthermore, approximately 30-50\% of refugee claimants will become Canadian citizens, so to deny health care to future Canadians is inequitable and inhumane especially considering the heartache that most refugees had to go through to get to Canada in the first place (Arya et al. 1876). Arya et al. claim that the effects of these changes will only entrench inequalities among classes of refugees and Canadian citizens even further, will barely address fraud within the current system, and will only create more costs in the future (Arya et al. 1876). For them, "the changes to the IFHP represent a profound shift in Canada's approach to migration and its humanitarian principles and obligations" (Arya et al. 1876). Canadian healthcare organizations such as the Canadian Medical Association, the Canadian Nurses Association and the Canadian Pharmacists Association, the Royal College of Physicians and Surgeons of Canada, the Canadian Dental Association, the Canadian Pharmacists Association, the College of Family Physicians of Canada, the Canadian Association of Optometrists, and the Canadian Association of Social Workers all signed a letter to protest the changes to the IFHP on May 18, 2012 (Eggerston 279).

Marwah effectively discusses the problem from the perspective of health service providers. There is a lot of confusion in trying to navigate the revised IFHP as a result of additional administrative tasks that are required to determine if people are eligible for coverage. The new IFHP has been criticized by health service providers and health care professionals for being time-consuming and an unrealistic expectation for those health providers who now have an increased administrative burden (Marwah 6). Furthermore, the changes to the IFHP have 
increased the use of emergency rooms for issues that could have been treated outside of the emergency room, therefore slowing the process down (Marwah 2). As a result we are seeing extra stresses being placed on the system making it harder for health care professionals to do their jobs effectively. Marwah's study found that hospitals in the Greater Toronto Area such as Toronto Western, Toronto General, Princess Margaret, and the Toronto Rehab Institute all “estimated a bill of $\$ 800000$ for services delivered to the uninsured in its emergency department alone. These figures raise two important issues. First, the shift in costs from the federal government to provinces for refugees with PHPS coverage, and second, the risk of increased costs because of delayed care" (Marwah 11), The governments' decision has led to confusion for both health care providers, as well as refugees who now are unsure of what coverage they are entitled to and therefore end up avoiding health care facilities, making their situations even worse.

The advocates' rights based approach can be greatly understood from a statement by Audrey Macklin, Professor and Chair in Human Rights Law at University of Toronto. She stated that:

this decision [from July $4^{\text {th }}$ ] is a victory for human rights, for human dignity, and for compassion. The decision makes it clear that a government cannot deliberately subject human beings to physical and emotional suffering as a means of punishing them for seeking refugee protection. Asking for refugee protection is not a crime. Today's judgement is consistent with the Charter of Rights and Freedoms, Canada's international legal commitments, and values that make us proud to be Canadian (Canadian Association of Refugee Lawyers (CARL), July $4^{\text {th }}$ ). 
Similarly, Lorne Waldman, President of CARL stated that "these cuts are inconsistent with the Canadian Charter of Rights and Freedoms and Canada's international obligations under the UN Refugee Convention. Worse than that, they are mean and callous. People with severe medical conditions are being put at risk; they are suffering unnecessarily for the saving of a pittance" (CARL, February $25^{\text {th }}$ ).

In an article by CARL, they claim that the new government system towards refugees, including but not limited to the changes of the IFHP is unrealistic as there is not enough time to find a lawyer, prepare paperwork, appeal negative decisions, or ask for an exception on humanitarian and compassionate grounds. (CARL: Challenging the Myths). They argue that the new system will result in grave injustices and say that it undermines Canada's human rights record (CARL: Challenging the Myths). Overall, there is an overwhelming concern for an infringement on human rights from international conventions as well as the Canadian Charter of Rights and Freedoms, and the horrendous treatment of an already vulnerable population.

To reiterate, the government has used a neoliberal ideology as justification to defend its position that says that the privatization of health care is better than providing free social services. The government thinks that making economically sound decisions will ultimately benefit Canadian society as they believe that the cuts are more cost-effective and will help Canada's economy. An analysis of this broader ideology and context has allowed for a better understanding of the different perspectives and why they use certain words, phrases, comments etc. when discussing this issue. This background will also be helpful when examining their arguments in the court case that will now be examined. 


\section{The Court Case: Introduction}

The paper will now outline the details of the Federal Court of Appeal's decision that ultimately rejected the changes to the Interim Federal Health Program. In doing so, it will examine both the applicant and respondent frames for their arguments in front of the court and Justice MacTavish, as well as their frames and discourse towards the Canadian public. When looking at the arguments before the court, the paper will specifically look at the decision that Justice MacTavish rendered on July $4^{\text {th }}, 2014$ as it lays out all of the arguments from each perspective. When looking at dominant and alternative discourses directed at the general public, I have examined the CIC website, media outlets, speeches, policy relevant texts and organizational statements from advocate organizations. Before unpacking the arguments within the document, the paper will provide a brief background and summary of the dominant issues that were discussed throughout. The parties involved in this case on the applicants side are Canadian Doctors for Refugee Care, The Canadian Association of Refugee Lawyers, Daniel Garcia Rodriguez, Hanif Ayubi and Justice for Children and Youth. This paper mainly focuses on the advocates' argument as a collective as going into details about the specific experiences of Daniel Garcia Rodriguez and Hanif Ayubi is beyond the scope of this paper. That being said, their experiences should not be overlooked as they are just two examples of the many refugee claimants and asylum seekers that have been severely impacted by the changes to the IFHP. The respondents in this case are the Attorney General of Canada and the Minister of Citizenship and Immigration. The main issues that have arisen in this case are: (i) whether the duty of procedural fairness ${ }^{5}$ was breached by the Governor in Council since there was no opportunity for

\footnotetext{
${ }^{5}$ Procedural Fairness ensures that a person or group "receive a fair and unbiased hearing before a decision is made that will impact on their rights or interests" (Procedural Fairness Guide 2). Furthermore, "a decision -maker must inform the person of the case against them, give the person a right to be heard, not have a personal interest in the
} 
stakeholders to participate in the decision-making; (ii) whether the two Orders in Council (OICs) in June 2012 by the executive branch of the government were ultra vires $^{6}$; (iii)- whether the changes breached obligations under international conventions that Canada is a signatory to, specifically the Convention on the Rights of the Child (CRC) and the Convention on the Status of Refugees; and (iv) whether the changes violate sections 7, 12, and 15 of the Canadian Charter of Rights and Freedoms (MacTavish 76-77). I will now provide brief definitions of the relevant sections of the Charter that can be referred to when reading the various perspectives. Section 7 of the Charter "provides that everyone has the right to life, liberty and security of the person and the right not to be deprived thereof except in accordance with the principles of fundamental justice" (The Constitution Acts 55). Section 12 of the Charter "provides that everyone has the right not to be subjected to any cruel and unusual treatment or punishment" (The Constitution Acts 56). Lastly section 15 (1) of the Charter provides that "every individual is equal before and under the law and has the right to equal protection and equal benefit of the law without discrimination and, in particular, without discrimination based on race, national or ethnic origin, colour, religion, sex, age or mental or physical disability" (The Constitution Acts 56). These are the pressing issues that are debated upon throughout the case, and will be examined from the applicant perspective, the respondent perspective, and what the Federal Court of Appeal's ruled through the use of Critical Discourse and Critical Frame Analysis. The chart below shows a breakdown of how I have used my methodological approach (CDA and CFA) to construct the frames of the various perspectives. The chart highlights the themes surrounding the frames, and

outcome of the decision, and only act on relevant information or evidence" (Procedural Fairness Guide 2-4). (For more detailed information refer to Queen's University's procedural fairness guide)

${ }^{6}$ Ultra Vires means 'beyond the powers'. It “describes actions taken by government bodies or corporations that exceed the scope of power given to them by laws or corporate charters" (Legal Information Institute: Ultra Vires). 
shows what frame types are associated with each perspective. These frames and frame types will be discussed in greater detail in the next three sections of the paper.

\begin{tabular}{|c|c|c|c|}
\hline Stakeholders & Frames Constructed & $\begin{array}{c}\text { Keywords \& } \\
\text { Themes }\end{array}$ & $\begin{array}{c}\text { Frame Types } \\
\text { Associated }\end{array}$ \\
\hline Applicants & $\begin{array}{l}\text { 1) Ethical Issues: Changes to } \\
\text { the IFHP are seen as } \\
\text { unethical } \\
\text { 2) Critique of cost saving } \\
\text { 3) Refugees now face } \\
\text { increased vulnerability }\end{array}$ & $\begin{array}{l}\text { Discrimination } \\
\text { Health Care Hierarchy } \\
\text { Rights Violations } \\
\text { Needless Pain and } \\
\text { Suffering } \\
\text { Costs Downloaded } \\
\text { Effects on Innocent } \\
\text { Children }\end{array}$ & $\begin{array}{l}\text { 1)Risk } \\
\text { 2)Information } \\
\text { 3)Collective Action }\end{array}$ \\
\hline Respondents & $\begin{array}{l}\text { 1) Containing financial costs } \\
\text { 2) Abuse generosity of } \\
\text { Canadians/Ensure fairness to } \\
\text { citizens } \\
\text { 3) Defend integrity of } \\
\text { refugee system and deter its } \\
\text { abuse }\end{array}$ & $\begin{array}{l}\text { Refugee Reform } \\
\text { Deterrence } \\
\text { Financial Burden } \\
\text { Genuine vs. Bogus } \\
\text { Alternative Options } \\
\text { Effect on Canadian } \\
\text { Citizens }\end{array}$ & $\begin{array}{l}\text { 1)Issue } \\
\text { 2)Identity } \\
\text { 3)Characterization }\end{array}$ \\
\hline $\begin{array}{l}\text { Federal } \\
\text { Court of } \\
\text { Appeal's }\end{array}$ & $\begin{array}{l}\text { 1) Taking away the human } \\
\text { dignity of refugees } \\
\text { 2) Against public standards } \\
\text { of decency / cruel and } \\
\text { unusual treatment } \\
\text { 3) Gaps, inconsistencies, } \\
\text { lack of evidence }\end{array}$ & $\begin{array}{l}\text { Stereotypes Perpetuated } \\
\text { Disadvantaged Group } \\
\text { Human Dignity } \\
\text { Intentional Targeting } \\
\text { Inconsistent Evidence } \\
\text { Inferior Treatment for } \\
\text { DCO Claimants }\end{array}$ & $\begin{array}{l}\text { 1)Risk } \\
\text { 2)Information } \\
\text { 3)Collective Action }\end{array}$ \\
\hline
\end{tabular}




\section{The Court Case Section One: The Applicants}

The main arguments that the applicants make are that the changes to the IFHP breach Canada's obligations under the CRC as well as the Convention Relating to the Status of Refugees. The applicants also argue that the IFHP changes violate the Canadian Charter of Rights and Freedoms, specifically sections 7, 12, and 15 (MacTavish 7). Therefore, as previously discussed the applicants are framing their arguments and justification through a humanitarian/human rights perspective. They understand this issue to be an ethical one and view these changes as inhumane and unjust. Therefore, after analyzing their discourse, the three dominant frames that that I found the applicants have used are: 1) Ethical Issues: changes to the IFHP are seen as unethical 2) Critique on cost saving and 3) Refugees now face increased vulnerability. When conducting frame analysis, the types of frames that I found which correspond with the applicants' argument are Risk and Information frames, and Collective Action Frames. These frame types are summarized below and will be discussed in more detail after an analysis of the frames and themes found within the advocate literature.

\section{APPLICANT FRAME TYPES}

\begin{tabular}{|c|c|}
\hline Frame Types & Description \\
\hline Risk and Information Frames & $\begin{array}{l}\text { - Depend on the parties' interest in the } \\
\text { issue } \\
\text { - Depend on expertise, training, exposure } \\
\text { to the situation } \\
\text { - Familiarity with risks and impacts } \\
\text { associated with the issue being debated }\end{array}$ \\
\hline Collective Action Frames & $\begin{array}{l}\text { Emergent, action-oriented sets of } \\
\text { beliefs and meanings } \\
\text { - Developed to inspire social movement } \\
\text { activities to attract public support } \\
\text { - Broken down into Injustice, Agency, } \\
\text { Identity }\end{array}$ \\
\hline $\begin{array}{c}\text { Frame Alignment: Frame } \\
\text { Amplification }\end{array}$ & $\begin{array}{l}\text { - Meanings are clarified and strengthened } \\
\text { - Understand how an issue is connected } \\
\text { to a person's life }\end{array}$ \\
\hline
\end{tabular}


- Reduced ambiguity and uncertainty

\section{A) Applicant Frame One: Ethical Issues: Changes to the IFHP are seen as unethical}

Doctors have expressed concerns about the ethical issues that they have been forced to deal with as a result of these changes to the IFHP. For example, in his cross-examination, Dr. Rashid explained that:

once you see somebody who has pneumonia, and you've ruled out TB, what if they're still sick? Are we supposed to then just say, I'm sorry, your coverage is finished, please move on? Once you assume care for an individual I think ethnically it's highly problematic to say two visits, three visits, sorry you don't have TB. We don't care what you have, please move on (MacTavish 42).

The applicants argue that the lives and security of targeted groups of refugees are being jeopardized and believe that their Section 7 rights have been infringed upon, specifically the rights to life and to security of the person. They argue that these changes expose refugees to the risk of not having necessary health care, further putting their lives and security at risk (MacTavish 123).

Changes to the IFHP were subject to cabinet confidentiality because they were effected through a budget process, as a result, there was no notice or consultation with stakeholders prior to the OICs even though this decision would affect provinces, patients and health care providers (MacTavish 101). Furthermore, "the applicants say that this breached the general duty of fairness owed to stakeholders by the executive branch of government and was...contrary to stakeholders' legitimate expectation that they would be accorded participatory rights before any fundamental changes were made to the IFHP" (MacTavish 101). Though there is no obligation on the 
executive branch of the Canadian government to provide health insurance coverage to refugee claimants in Canada, the applicants argue that since they have been providing coverage since 1957, they have to now do so in a manner that does not conflict with the Charter. To back up their argument, they quote a Supreme Court ruling "even though the state may be under no obligation to provide a benefit, once it elects to do so, the benefit must be provided in a nondiscriminatory manner and in some circumstances will require governments to take positive action" (MacTavish 137).

Another issue that the applicants have is that the changes to the IFHP are "unlawful because the 2012 OICs are ultra vires the executive branch of the government...the applicants say that the Governor in Council simply lacked the authority to make the modifications to the program" because this decision was beyond the power of the executive branch of government (MacTavish 89). In addition, the applicants assert that the 2012 IFHP changes "constitutes cruel and unusual treatment of a poor, vulnerable and disadvantaged group by the executive branch of the Canadian government" (MacTavish 142) and therefore violate section 12 of the Charter.

The applicants further their argument by stating that Canada is going against articles in conventions that the country is a signatory to such as the CRC and the Convention Relating to the Status of Refugees. Article 2 (1) of the CRC states that "state parties are required to respect and ensure the rights set forth in the present convention to each child within their jurisdiction without discrimination of any kind, irrespective of the child's or his or her parent's or legal guardians race, color, sex, language, religion, political or other opinion, national, ethnic or social origin, property, disability, birth or status" (UNHR: CRC). Article 3(1) of the CRC "provides that in all actions concerning children, whether undertaken by public or private social welfare institutions, courts of law, administrative authorities or legislative bodies, the best interests of the 
child shall be a primary consideration" (UNHR: CRC). The United Nations Committee on the Rights of the Child has stated that "a child's right to health is central in assessing a child's best interests" (MacTavish 115). Thus, these changes have negatively affected innocent children, some of whom receive no coverage whatsoever and are ethically irresponsible. Children who are mainly affected by the changes to the IFHP are those who are from DCO countries such as Mexico and Hungary who only have PHPS coverage (MacTavish 159). Children who are only entitled to a PRRA are not entitled to any health care coverage, even if they have a health condition that impacts public health and safety (MacTavish 162). Furthermore, some children may not receive health care at all if they have a family member that had a previously unsuccessful claim on behalf of the family (MacTavish 162). Thus, children from DCO's or caught up in complicated legal proceedings might receive no health care coverage whatsoever for an extended period of time.

The effects on children, who are forced to do what their parents tell them to and had no control over coming to Canada, is a highly controversial and ethical issue as they are among the most vulnerable in our society and are victims of this cruel policy change. Furthermore, "there are other communicable health conditions such as conjunctivitis, head lice, scabies and diarrhea, all of which can jeopardize the health of school children, in particular, these conditions are not on the list of communicable diseases for which treatment will be available under the Public Health and Public Safety component of the IFHP" (MacTavish 231). Children affected by these medical conditions may not be able to go to school, disadvantaging them even further. This could also lead to the infection of other children and adults, thereby threatening public health and the safety of refugees and Canadians (MacTavish 231). 
In the Convention Relating to the Status of Refugees Article (3) "provides that contracting states shall apply the provisions of this Convention to refugees without discrimination as to race, religion, or country of origin" (UNHCR 17). This "Article has been interpreted not just as general anti-discrimination provision, but as one prohibiting discrimination between refugee claimants and refugees and the nationals of the host country, as well as prohibiting discrimination between classes of refugees" (MacTavish 112). However, the applicants argue that the new IFHP provides inferior health coverage to refugees from DCO countries, which constitutes discrimination. The applicants claim that this discrimination is contrary to section 15 of the Charter of Rights and Freedoms that deals with the issue of equality.

In discussing the differential treatment awarded to those from DCO countries, the applicants argue that the respondents "have no data that would suggest that the health needs of refugee claimants from DCO countries are any less than those of refugee claimants from nonDCO countries, nor do they have any evidence to suggest refugee claimants from DCO countries are any more able to pay for their health care than are refugees from non-DCO countries" (MacTavish 196). Therefore, the applicants argue "the 2012 OICs draw a distinction between classes of refugee claimants based upon their country of origin. They provide a lower level of health insurance coverage to individuals coming from DCO countries than is provided to refugee claimants coming from non-DCO countries" (MacTavish 171). One health care provider asks "how should we tell a recently arrived mother fleeing from danger and suffering from depression that neither she nor her child is eligible for care, simply because of their country of origin" (MacTavish 156)? This is an extremely ethical issue for those that are in the health care profession and want to look after all of their patients equally. When discussing this apparent 
health care hierarchy, the applicants assert that it is making the lives of some refugees less important, or less worthy of protection and health care than others.

In addition, they site Article 7 (1) of the Refugee Convention which "provides that except where this Convention contains more favorable provisions, a Contracting State shall accord to refugees the same treatment as is accorded to aliens generally" (UNHCR 17). They argue that since Canada allows students or persons on long term work visas to access universal health care as long as they have been authorized to remain in the country, "resettled refugees and refugees recognized within Canada's refugee determination system should be entitled to similar health insurance coverage" (MacTavish 113). Dr. Phillip Berger has stated that:

Minister Chris Alexander and the Conservative government are continuing their reckless conduct rather than acting responsibly on a serious public policy issue and respecting a court order...every move this government has made on refugee health has been spurious, vindictive, or sneaky. It is time for Minister Alexander to come clean, stop playing games, and do as he was ordered by the court. Cruelty is costly (CARL December 4, 2014).

This is a view that many health care professionals agree with including Dr. Rachlis, Dr. Anderson, Dr. Rummens, Dr. Ornstein, Dr. Daneman, Dr. Berger, Dr. Rashid, Dr, Feder, Dr, Wong and Dr. Caulford who either provided affidavits for the case or offered their professional medical opinion on this issue. Dr. Rashid was quoted saying that "we are surprised and troubled that the government would quietly abolish a health program that had worked so well for more than half a century" (CARL December 4, 2014).

Furthermore, Canadian Doctors for Refugee Care (CDRC) state that "the government's cuts to health services to refugees residing in this country -some of whom will have just escaped 
war, violence or famine, is unjust and counter to Canada's long history of compassion and openness" (CDRC July 4, 2014). The Canadian Pharmacists Association has claimed that “denying health care and pharmaceutical care to refugees will only make them sicker, deteriorate their health and make it more difficult for them to integrate into our society and become productive citizens. In return, this will require more hospitalizations and will be more costly for the overall health care system" (Hanhan October 2012). The discourse that these organizations use is clearly rooted in humanitarianism. For example, the Canadian Pharmacists Association has said that "this country has a global obligation to accept refugees, and has a reputation for caring for refugees on humanitarian and compassionate grounds. As pharmacists and health care practitioners, we need to continue to fight for all the changes to be rescinded. It is the right thing to do" (Hanhan October 2012). They are clearly outlining the humanitarian and compassionate nature of Canada's previous health care system for refugees and the fact that it is inhumane and indecent to deprive refugees of this fundamental human right. This frame of Ethical Issues has shown that the applicants argue that these changes are ethically irresponsible, and that it is hard for health care professionals to uphold a policy that is so corrupt.

\section{Applicant Frame Two: Critique of Cost Saving}

The second popular frame that I found the applicants used to shape their argument is the fact that these changes will not produce any cost savings. Since there will now be a shift from who is actually providing health care, whether it be a charity, pharmaceutical company, the provinces etc., it is clear that the costs of refugee health care will now be downloaded to others. However, as it is continuously argued throughout the case, it is unclear that changes will actually result in savings for Canadian taxpayers (MacTavish 42). Dr. Rachlis, a medical specialist and Adjunct Professor at University of Toronto stated that "any cost savings achieved by cutting insurance for 
primary health care may be outweighed by higher subsequent costs for other health care services, especially hospital services" (MacTavish 43). In addition, the CARL has stated that "the cuts may well increase government health costs in the long run as emergency care generally costs much more than the preventive care which is being eliminated" (CARL February 25,2013).

At least 21 medical organizations in Canada expressed concerns about the changes to the IFHP and argued that "the cost saving of providing care to vulnerable individuals would be downloaded to provincial social support programs, community-based programs, the charitable sector and others" (MacTavish 36). Dr. Rachlis “outlines what he says is the 'optimal method' to determine whether the 2012 changes to the IFHP have actually resulted in any net public sector cost savings.[He] states that, to the best of his knowledge, the Government of Canada has not carried out any such analysis" (MacTavish 28-29). Therefore, the Canadian government is making a huge statement and claim with no supported factual evidence to back-up if what they say is true. A study by Arya et al. states that "the annual cost of coverage per refugee under the program may be somewhere between $\$ 562$ and $\$ 660$, substantially less than the $\$ 6141$ spent per capita on health and social services for the average Canadian" (Arya et al. 1876).

Barbara Mildon, a spokesperson for the Canadian Nurses Association released a statement that said the IFHP:

is not to blame for our country's overcrowded emergency departments or long wait times, nor is it the reason that more than four million Canadians have no primary care provider. The fifty-nine cents this program costs each Canadian taxpayer is not an 'unaffordable luxury'. I have a hard time believing that anyone wouldn't pay fifty-nine cents if it means helping a young boy get asthma 
medication, a pregnant woman get treatment for preeclampsia or a cancer patient get chemotherapy (Mildon July 12, 2013).

They also agree that these cuts will not save money in the long run and will be downloaded to the provinces (Mildon July 12, 2013). It appears that the money that 'might' saved after all of this confusion and chaos is not even enough for Canadian taxpayers to worry about in the first place. These extremely inhumane cuts to health care that supposedly 'save Canadian tax dollars' barely impacts Canadian citizens. Therefore, the advocates argue that these cuts will only increase spending in the long run, as the preventative care that many refugees are no longer entitled to is a lot cheaper than emergency care.

\section{Applicant Frame Three: Refugees now face increased vulnerability}

The third and most dominant frame that is used by the applicants, advocate organizations and doctors is that refugees are one of the most vulnerable groups in Canadian society, and that these changes are unjust and unfair. Justice MacTavish stated that "in addition to causing needless pain and suffering, the failure to treat conditions will exacerbate the future health care needs of affected individuals" (MacTavish 38). In addition, Dr. Rachlis argued that "individuals without health insurance are less likely to seek medical care which can increase the risk of adverse health effects...this results in poorer overall health and higher use of hospital services, both emergency rooms and acute care beds" (MacTavish 42). When discussing the situation of Mr. Akhtar, the Premier of Saskatchewan was quoted saying "it is unbelievable...the decisions that have been taken federally have been having this impact on people who are clearly the most vulnerable" (MacTavish 57). As such, advocates are saying that this is a vulnerable group and these changes are ultimately cruel and unusual treatment according to section 12 of the Charter. Furthermore, a 
nun who was assisting Mr. Akhtar said "the amount of anxiety and stress that has been added to his situation was awful" (MacTavish 57-59) as Mr. Akhtar and others were and are burdened with immense psychological stress. In all of the situations described in the court case, the refugees were burdened with anxiety and stress, making them even more vulnerable. When medical bills began to add up that they could not pay, it made things even worse for them.

The medical organizations on the applicants' side claimed that refugee claimants that do not have access to provincial care will no longer have upfront health services available to them. They argue that those that have medical conditions that are undiagnosed and untreated will have increased medical complications in the future. If they are not able to access proper health care and have pressing medical concerns, it makes it much more difficult for newcomers to Canada to learn English or French, attend school or enter the job market (MacTavish 156), increasing their vulnerability. Furthermore:

the applicants point out that by simply bringing the complement of adjudicators on the IRB up to full strength, the government was able to greatly reduce the length of time that cases languished before the IRB. That has, in turn, helped to shorten the time that unsuccessful claimants remain in Canada, reducing the period for which they are eligible for IFHP benefits. The government is also ensuring that removals are carried out more quickly after refugee claims are rejected, again reducing the time that claimants are eligible for IFHP benefits, reducing program costs accordingly. One can assume that speeding up the removals process even more would result in further cost savings to the IFHP, without requiring a reduction in the level of benefits provided by the program (MacTavish 243). 
Since the government reformed Canada's entire refugee determination system, they have already met most of the goals that they set out to achieve, and have saved millions of tax dollars without the need to reform the IFHP. Dr. Philip Berger asked:

how Alexander can declare any claimants to be bogus when the changes apply to those who haven't yet had hearings to determine their status...their claims were lawfully within our borders....they've not had a determination yet, yet through some clairvoyant power of deduction, Minister Alexander seems to know that they're bogus before they've had their hearing. Perhaps he can explain that finally after the last year of accusing all refugee claimants of being bogus (Payton July 4, 2014).

The government has claimed that only claimants who are considered 'bogus' are being denied health care coverage in Canada. However Doctors Rashid and Berger have pointed out that "refugee claimants from DCO are lawfully within our borders, following the rules, awaiting their refugee determination hearing. They are not failed (or 'bogus') claimants unless they are unsuccessful at their hearing" (Rashid and Berger July 5, 2013). Furthermore, "failed refugee claimants do not deserve coverage and should leave the country [according to the government] yet some failed claimants are from 'moratorium' countries, such as Iraq and Zimbabwe, to which the government does not deport anyone. [As a result] they end up with virtually no coverage for years in some cases" (Rashid and Berger July 5, 2013). This puts these people in an extremely vulnerable situation for a long period of time.

Justice for Children and Youth (JFCY) is one of the applicants in this case and has put out several statements regarding the effects that these cuts have on refugee youth. They are 
concerned with the fact that youth could be without health insurance for numerous years, and that these changes are contrary to the CRC. In addition, they claim that "there will be no ability to diagnose and manage mental health conditions which are known to affect child refugees at higher rates due to trauma related to the refugee experience" (Sanchez March 11, 2013). They quote the Canada Health Act when they say its primary objective "is to protect, promote and restore the physical and mental well-being of residents of Canada and to facilitate reasonable access to health services without financial or other barriers" (Sanchez March 11, 2013). Furthermore, they quote Article (24) of the CRC which discusses "the right of the child to the enjoyment of the highest attainable standards of heath and to have access to facilities for the treatment of illness and rehabilitation of health. [The CRC] states that 'signing parties shall take appropriate measures to ensure the provision of necessary medical assistance and health care to all children with emphasis on the development of primary health" (Sanchez March 11, 2013). Therefore, JFCY believes that the government is acting contrary to the international conventions that Canada is a signatory to and vulnerable children are feeling the negative effects, thereby jeopardizing their health and well-being.

In a letter from a group of national healthcare associations addressed to Jason Kenney, they claim that:

in order to ensure long-term fiscal responsibility, to ensure the health and wellbeing of Canadian society's vulnerable populations, and in order to uphold Canadian principles of compassion and inclusiveness, we as health care providers are asking you to revise or rescind this policy announcement. We would be pleased and prepared to work with your officials to examine ways in which services for refugee claimants can be delivered more efficiently and effectively- 
however, a wholesale cancellation of supplemental benefits in our view is counterproductive (Linton et al. May 18, 2012).

The national healthcare associations listed above have come together to protest these changes to the IFHP. Their solidarity, and the fact that the applicants continuously discuss the importance of Canada's humanitarianism, compassion, and inclusiveness is an extremely persuasive argument by the people that are closest to refugees affected by these changes. Their argument is hard to ignore as their persistence is a tribute to the fact that the government's changes were wrong and a form of cruel and unusual treatment, discrimination, and contrary to international conventions.

\section{B) Applicant Frame Types: Risk, Information, and Collective Action Frames}

Though I have broken the applicants' argument down into three different frames, all of the arguments are under the same umbrella of humanitarianism and human rights and are essentially saying the same thing. These changes are morally and ethically wrong, unjust and inhumane and contrary to the rights embedded in the Canadian Charter of Rights and Freedoms and need to be reversed. The paper will now look at frame types that can be applied to the applicants' argument. Risk and Information frames are frames "that yield highly variable assessments about the level and extent of a particular risk" (Kaufman et al.). These frames depend on the parties' interest in the issue, as well as their expertise, training, exposure to the situation, and familiarity with risk and impacts associated with the issue being debated (Kaufman et al.). For example, "people who are used to working and traveling in war-torn areas, have a far different assessment of the risks of such activities than people who don't (who thus are more likely to see the risk of doing so to be unacceptably high)" (Kaufman et al.). Likewise, people who regularly work with refugees, especially health care professionals and refugee advocates have a much clearer understanding and assessment of the risks associated with these cuts than 
government authorities that are far removed. The assessment of the risks that are associated with the changes to the IFHP (such as discrimination, effects on children, lack of cost savings, negative long-term health effects) as well as promotion of information and facts is extremely evident when looking at the Ethical Issues, Critique on Cost Saving, and Vulnerability frames of the applicants.

Another type of frame that can apply to the applicants' argument is the use of Collective Action Frames. These frames are "emergent, action-oriented sets of beliefs and meanings developed to inspire and legitimate social movement activities and campaigns designed to attract public support" (Taylor 511). Collective Action Frames can be broken down into three parts, injustice, agency and identity. Injustice refers to the feeling of moral outrage by activists and advocates. Agency refers to how people feel empowered to change conditions and policies, and identity "refers to the process of defining the 'we' or 'us' usually in opposition to 'they' or 'them"' (Taylor 511). Thus, in this case the advocates focus on 'we' and 'us' and how everyone in Canada should be treated fairly, regardless of their status because we are all humans entitled to the human rights enshrined in the Constitution. These frames can also be considered injustice frames "because they are developed in opposition to already existing, established and widely accepted frames [that] serve to pinpoint, highlight and/or define unjust social conditions" (Taylor 511). Therefore, advocates have to try to successfully counter the dominant-hegemonic frames and their ideological underpinnings.

Frame alignment seeks to "bridge individual goals and identities with goals of the general society" (Taylor 512). There are four kinds of frame alignment, however, the one that directly relates to this situation is frame amplification which "refers to the process whereby the meanings and interpretative framework of an issue are clarified and strengthened such that people can see 
how the issue is connected to their lives. Frame amplification also reduces the ambiguity and uncertainty that might prevent people from caring about an issue and participating in it" (Taylor 512). The advocates are against the dominant social construction of refugees that the government has created that sees refugees as 'bogus' and 'queue jumpers' and look at this issue on a human level. They do this by bringing up issues of accessibility, equality, and human rights, and have conducted frame amplification to try to appeal to the Canadian public and receive support for their counter-dominant opinions. These frames are trying to counter the dominant discourse and argument of the government in saying that their arguments are largely speculative.

\section{The Court Case Section Two: The Respondents}

The next section of the paper will look at the main arguments that the respondents have used to justify their decision to modify the IFHP. This section will explore their argument through the use of the frames that the government has used to promote their perspective and decision to the general public as well as the federal court, by examining the discourse in the FCA document as well as statements by CIC and government officials that are available to the Canadian public. In analyzing these sources, I have concluded that the government's dominant neoliberal ideology, that sees refugees as 'bogus', 'illegal', 'queue jumpers' and 'criminals' can be broken down into three frames. The three frames that are the most dominant and will be explored in this paper that are; 1) Contain the financial costs of the IHFP 2) Abuse of the generosity of Canadians/Fairness to Citizens 3) Defend the Integrity of Canada's Refugee Determination System and Deter it's Abuse. The respondents state that the original purpose of the IFHP was never to provide health care coverage for everyone that arrives in Canada, but rather to "provide insurance coverage for urgent and essential health care to eligible beneficiaries for a limited and short duration" (MacTavish 13). They argue that the notion that refugees are 
abusing the Canadian system is not the issue that motivated their reform of the IFHP. Instead, these changes were seen as a way to support the government's overall objective of refugee reform in Canada. The cuts were another avenue through which the government would be able to deter unfounded refugee claims and encourage failed refugee claimants to leave Canada (MacTavish 19). The three main frames from the respondents that will be discussed below can be categorized into Issue, Identity and Characterization Frames. These types of frames are summarized below and will be analyzed after a discussion of the most dominant frames.

\section{RESPONDENT FRAME TYPES}

\begin{tabular}{|c|c|}
\hline Frame Types & Description \\
\hline Issue Frames & $\begin{array}{l}\text { - Political frames } \\
\text { - Originate from political leaders and } \\
\text { spread through the mass media } \\
\text { - Communicate information as a political } \\
\text { strategy }\end{array}$ \\
\hline Specific Issue Frames & $\begin{array}{l}\text { - Links governmental activities with } \\
\text { targets in society } \\
\text { - Promote policy initiatives } \\
\text { - Identify why decisions are necessary }\end{array}$ \\
\hline Identity and Characterization Frames & $\begin{array}{l}\text { - How individuals conceptualize } \\
\text { themselves and others to be } \\
\text { - Frames are stable, provide a solid base } \\
\text { for political maneuvering } \\
\text { - Use of social construct frames to foster } \\
\text { alliances and enemies }\end{array}$ \\
\hline
\end{tabular}

\section{A) Respondent Frame One: Contain the financial costs of the IFHP}

Perhaps the most dominant frame and argument from the respondents is the fact that the IFHP is a huge financial burden to the government and to Canadian taxpayers, and these cuts dramatically reduce the amount of money spent on the program. The respondents claim that "the IFHP cost Canadian taxpayers $\$ 50,600,000$ in $2002 / 2003$ and almost $\$ 91,000,000$ in 2009/2010” (MacTavish 17). They saw this increase as way more than what should be spent on refugee and 
asylum health care and decided that a change needed to be made. Therefore, one of the driving forces of their decision was to contain costs when reforming the IFHP. CIC "says that the IFHP costs $\$ 84$ million annually and that the changes that took effect June 30, 2012 are anticipated to save approximately \$20 million per year over the next five years" (CHA 5). Alexander stated that as a result of the changes to the IRPA in 2012 over $\$ 600$ million has already been saved, and approximately $\$ 1.6$ billion will be saved in the first 5 years. However, only $\$ 20$ million per year of that total is 'supposedly' being saved as a result of the cuts to the IFHP. It begs the question of why it is necessary to go to such great lengths to ensure refugees are not receiving adequate health care when it is a fundamental human right, while there are still other ways that costs are being realized.

The IFHP was originally intended to provide short-term medical coverage to eligible individuals, however, the respondents argue that this purpose has changed over time and that the increasing costs of the IFHP is attributed to how long people are eligible to receive benefits (MacTavish 17). For example, "while the average period of IFHP eligibility was 584 days in 2003, the average eligibility period had climbed to 948 by 2012” (MacTavish 17). Since the length of eligibility was increasing, the costs associated with the program were increasing as well. The CIC website explains that "too many tax dollars are spent on asylum claimants who are not in need of protection" and that there are a large number of claimants from DCO countries (CIC Backgrounder: DCO 2012). These 'unfounded' refugees are seen as a burden on the Canadian economy. By restricting work permits and the availability of social assistance programs for people from DCO countries, the government is denying access to the labour market, and the benefits that are associated with working in Canada, in hopes that they do not 
prolong their stay (CIC Backgrounder: DCO 2012), thereby reducing the amount of tax dollars spent on them.

At the federal court, the respondents argued that "governments have finite resources to spend on health care for everyone present in Canada, including Canadian citizens, permanent residents, refugee claimants, refugees, failed claimants and those with no legal status or claims whatsoever" (MacTavish 212-213). They state that the government is not able to fund all health services in Canada and that as a result, difficult decisions have to be made. (MacTavish 212213). The applicants say that the respondents breached procedural fairness because stakeholders were not able to weigh in on the changes. In response, the respondents deny that there was any duty of fairness owed to the applicants because CIC did not have a legal duty to the stakeholders, and they claim they did engage with stakeholders between April and June 2012 where they were able to review the changes. They also stated that CIC explained the policy reforms through numerous public briefings (MacTavish 105). Furthermore, the respondents argue that "the federal government has the inherent power to spend the money that it raises through its taxing power in the manner that it chooses to authorize...” (MacTavish 94). Thus, the neoliberal ideology is readily apparent in this frame that is more concerned with the costs of the system than what the long term effects will be for refugees and asylum seekers.

\section{Respondent Frame Two: Abuse of the generosity of Canadians/Ensure Fairness to Citizens}

The second popular frame to be examined is the frame that is concerned with the affect that the IFHP has on Canadian citizens themselves. The government is very concerned with the generosity of Canadian citizens being abused by 'bogus' claimants and they want to ensure that Canadian citizens are being treated fairly. Justice MacTavish quoted Jason Kenney's speech where he said that: 
Canadians have been clear that they do not want illegal immigrants and bogus refugee claimants receiving gold-plated health care benefits that are far better than those Canadian taxpayers receive. Our government has listened and acted. We have taken steps to ensure that protected persons and asylum seekers from nonsafe countries receive health care coverage that is on the same level as Canadian taxpayers receive through their provincial health coverage, no better. Bogus claims from safe countries, and failed asylum seekers, will not receive access to health care coverage unless it is to protect public health and public safety. Shamefully the NDP and Liberals support bogus and rejected asylum seekers receiving gold-plated health care benefits. We disagree. Those who have been through our fair system and are rejected should respect Canada's laws and leave the country (MacTavish 19).

This speech is a good reference point for understanding the dominant government discourse that has emerged when talking about refugees. From this speech it is clear that one of the dominant arguments that the respondents are making is that they do not want refugees to abuse the generosity of Canadian citizens, and that they should not be able to receive better health care than Canadian citizens themselves. In response to the claims that they are breaching Section 15 of the Charter of Rights and Freedoms and are discriminating against different classes of refugees, "the respondents say that by granting refugee claimants from DCO countries a level of state funded health insurance coverage, the Governor in Council is not 'perpetuating prejudice or stereotyping', rather it is simply recognizing that even though these refugee claimants are from countries that are generally safe, non-refugee producing nations with health care systems that are comparable to Canada's own, they are deserving a minimum level of state-funded health care 
while they are in Canada making a refugee claim" (MacTavish 197). The respondents "deny that there has been any violation to section 15 on the basis of either the national or ethnic origin or the immigration status of IFHP beneficiaries" (MacTavish 171). They argue that "multiple countries have been labelled as DCO and that any distinction that may be made between foreign nationals of diverse origins does not constitute discrimination on the basis of national or ethnic origin" (MacTavish 171).

Jason Kenney has stated many times that Canadians are proud that we have a generous and humanitarian determination system, however, citizens will not tolerate the abuse or taking advantage of our system (Kenney February 16, 2012). In the same speech Kenney says "to be blunt, Canada's asylum system is broken. That's why Parliament passed the Balanced Refugee Reform Act in 2010. The Act contains long-needed improvements that will result in faster protection for real refugees and quicker removal of bogus refugee claimants" (Kenney February 16, 2012). He continuously pushes the 'fact' that the changes to the IFHP are protecting public health and safety, defending the integrity of the immigration system, and spending tax dollars wisely (CIC Archives April 25, 2012) and rarely mentions the refugees and asylum seekers, the people that the program is supposed to benefit from, in a positive light. The most common words used when describing refugees are 'bogus, failed, illegal, criminals, queue jumpers' etc. that all look at them as a negative burden for Canadian society.

Despite the argument that the applicants made about the respondents violating section 7 of the charter, the respondents argue that "there is no positive obligation on the government of Canada to provide health insurance coverage to those seeking protection...the 2012 OICs do not cause a deprivation of medical care, nor do they prohibit access to it" (MacTavish 125). They stress that any class of refugee who is ineligible for the IFHP is not inhibited from seeking 
coverage by other means (MacTavish 125). The respondents argue that the new IFHP is an ameliorative ${ }^{7}$ program and claim that sometimes when trying to help one group it is necessary for an ameliorative program to exclude other groups (MacTavish 173). Furthermore, the respondents argue that the:

IFHP funds health care 'treatment' at the expense of the state, but that no one is 'subjected' to the IFHP. The respondents contend that section 12 of the Charter is concerned with mandatory matters imposed by the state and is in no way analogous to an IFHP beneficiary's acceptance of medical 'treatment'. The IFHP does not prevent anyone from obtaining medical care: rather it offers and funds some health care services for eligible beneficiaries, who can access them if they choose, at state expense (MacTavish, 142).

As previously discussed, the respondents argue that even though certain people are no longer covered under the IFHP, there are other ways that they are able to receive medical care, and describe it as a "whole panoply of options ...these include provincial health insurance coverage that has been instituted to 'fill the gaps' created by the 2012 changes to the IFHP, as well as regular provincial or territorial insurance, private insurance, self-funding, and the good will of others" (MacTavish 64). They continue by saying that "the record is replete with examples of people benefitting from the goodwill of pharmaceutical companies, and from medical clinics for the uninsured" (MacTavish 64). Thus, the respondents claim that the changes to the IFHP and the ability of refugees to seek health care elsewhere means that this system is more fair for Canadian citizens, as their generosity is no longer being abused. Though some refugees may be able to find health care elsewhere, not everyone can be so lucky and base their health care on

\footnotetext{
${ }^{7}$ Ameliorate means to make better or to improve a situation (Collins Dictionary).
} 
whether or not an organization or company will take pity on them and cover their health care costs. The use of this frame by the government places focus more on Canadian citizens themselves and how they may be impacted by this program, rather than looking at the effects that these changes have had for refugees, and in doing so, have allowed much of the Canadian public to buy into this argument.

\section{Respondent Frame Three:}

\section{Defend the Integrity of Canada's Refugee Determination System/Deter its Abuse}

Jason Kenney was quoted as saying "we will not tolerate those who seek to abuse our generosity, including bogus asylum claimants, human smugglers and those who might represent a risk to Canadian security and safety" (Kenney June 29, 2012). This leads into the third and final frame of the respondents' perspective, which is concerned with the integrity of Canada's refugee system, as well as deterring abuse of the system. In 2012, Kenney described Canada's refugee determination system as 'dysfunctional and broken' and emphasized that the Balanced Refugee Reform Act would allow for a faster and fairer system (Kenney June 29, 2012). Chris Alexander has similar discourse when talking about refugees and Canada's determination system. He stated that "our reforms are not simply about cracking down on fraudulent or unfounded asylum claims, although this is a good thing. Our reforms mean that....by discouraging these bogus asylum seekers and sending them home more quickly, we're able to provide better service and faster protection for people who are actually in need of Canada's protection" (Alexander January 22, 2014). In the same speech, Alexander stated that: we all win as taxpayers, as government-service providers, and as humanitarians when those who jump the queue, those who abuse our generosity, those who take money or generate money for organized crime, those who refuse to leave when 
their claims are rejected, and those who take advantage of our social programs, are forced to play by the rules, are held accountable. Bogus asylum seekers are not entitled to the same benefits as taxpaying Canadians or genuine refugees. Neither are failed claimants, who by definition are not refugees. Their claims have failed and they have no right to remain in Canada, or to defy our laws by refusing to leave when ordered to do so (Alexander January 22, 2014).

When responding to the applicants' argument that Canada should uphold the commitment that it made by signing the Convention on the Rights of the Child as well as the Convention on the Status of Refugees, the respondents state that there is no clause that requires the CRC to provide and fund health care based on international law. They argue that obligations from international law based on conventions cannot succeed in court if Canada's parliament has not implemented them through legislation (MacTavish 118). Furthermore, the respondents state that articles from the Refugee Convention and CRC "have not been incorporated into Canadian law, and that the mere ratification of an international treaty does not give the treaty the force of law in Canada... and note that international law, whether binding or not, is not a source of domestic rights or remedies" (MacTavish 110). That being said, they have acknowledged that it can be a valuable interpretive aid when courts are determining a breach of the Charter of Rights and Freedoms (MacTavish 110). Jason Kenney has been quoted saying that "Canada will continue to exceed all of our international and domestic legal obligations-for example, our obligations under the Charter of Rights and the United Nations Conventions on Refugees and Torture" (Kenney February 16, 2012) however, it appears that the government has not stayed true to these commitments from the perspective of refugee advocates. 
The government has had an extremely negative response to provinces that have decided to fill the gap in health care for refugees that the federal government made. There has been a huge amount of criticism from CIC, which is ironic given that the government lists the provinces as one of the available alternatives that refugees have to access health care elsewhere. The "Ontario government has said it will pay for 'most hospital, primary, specialist, laboratory and diagnostics services provided in Ontario for refugee claimants living in Ontario, regardless of the status of their claim or the country they're from" (Alexander January 22, 2014). According to Alexander:

this means that people whose asylum claims have been rejected, including those who have access to health care in Europe, will be given health care paid for by Canadian taxpayers, while Canadians, including Canadian seniors, wait behind them. This decision is irresponsible, as it makes Canada -and Ontario in particular- a magnet for bogus asylum seekers. It is also unfair to taxpayers, who have to foot the bill, while their own access to health care suffers (Alexander January 22, 2014).

When discussing the fact that Ontario is providing coverage to claimants, Alexander stated that "simply arriving on our shores and claiming hardship isn't good enough. This isn't a self-selection bonanza, or a social program buffet" (Mas January 23, 2014). Yet, the restrictions placed are so limiting that genuine refugees/ refugees from DCO are now getting turned away as well. The respondents continuously focus on deterring abuse of the Canadian system and defending its integrity. (Mas January 23, 2014). While the changes to the IFHP were taking place, Kenney stated that: 
the real question is why were we providing them with tax-funded health insurance in the past? That's what Canadians have been asking us and that's why we've acted in this way... I would just say to the provinces, with respect, that I don't understand why they seem more concerned about providing supplementary health benefits like dental care and eye care to, for example, rejected asylum claimants than they are to their own citizens (Fitzpatrick June 29, 2012).

The discourse that the government has used when discussing this issue such as 'bogus' 'queue jumpers' 'abuse of the system' etc. has had a lasting effect on the general public who are beginning to buy into the government's argument. Former Immigration Minister Jason Kenney "has alleged that doctors who have documented cases of harm flowing from the cuts have 'purposefully altered' the facts and he labeled protesting doctors as 'militant leftists'. After a 19city National Day of Action on June 17 this year organized by Canadian Doctors for Refugee Care, Kenney denounced the doctors for an 'irresponsible and shameful attempt to further their unreasonable demands" (Rashid and Berger July 5, 2013). In this instance Kenney is trying to discredit doctor's professional opinions. However, the fact that the ten doctors from various cities across Canada that were mentioned above are all protesting these changes means that from the opinion of health care professionals, there is something fundamentally wrong with these changes. This frame, Defending Canada's Refugee System and Deterring its Abuse is echoed in most government discourses on the refugee health care debate, as well as refugees in Canada more generally. I will now discuss the frame types that fit with the respondents' perspective.

\section{B) Respondent Frame Types: Issue, Identity and Characterization Frames}

As previously stated, the respondents' arguments and frames can be understood through the frame types of Issue, Identity, and Characterization frames. Issue frames are purely political, 
have their origins from political leaders and generally use the mass media to spread their message (Jacoby 751). These frames are used to communicate information about an issue, or the government's interpretation of the issue to influence public perception as a political strategy (Ellis 48). Furthermore, though issue frames are categorized into general and specific, for the purposes of this paper only specific issue frames will be explained as they directly relate to the governments framing of this issue. As such, "a specific issue frame explicitly links governmental activities with targets in society. Statements of this type not only promote certain policy initiatives; they also identify the reasons that such steps are necessary, along with the beneficiaries (or victims) of government action" (Jacoby 751). For example, the frames of Containing Financial Costs and Abusing Generosity of Canadians can be seen as issue frames that try to justify government action in front of the Canadian public that reformed the refugee determination system and cut the health care system.

Identity and Characterization frames also relate to the frames that have been constructed for the respondents. These are frames that are "based on how individuals conceptualize themselves and others to be respectively" (Ellis 49). Thus, these frames look at how we (Canadians) see ourselves, as well as how others are seen and socially constructed. Importantly, "these types of frames are generally stable and persist regardless of external frames and events, providing a solid basis for political maneuvering. Social construct frames are powerful tools of elite frame communicators to foster alliances and enemies within a policy issue" (Ellis 49). Thus, within the government discourse, it appears that the frame of Defending the Integrity of Canada's Asylum System and Deterring its Abuse would fall into this category, as refugees have been constructed in such a way as to be 'criminals' and 'burdens to the system', making Canadians feel that they are being taken advantage of by refugees. 
All of the respondent frames appear to be focused on how the refugee health care debate affects Canadians. They are trying to frame this issue to make sure that Canadians are not being 'taken advantage of' and ensuring fairness, however, the results of their decisions have actually had no impact on fairness to Canadian citizens and have most likely increased costs for Canadian taxpayers, as will be discussed further in the next section. The respondents are framing their argument this way because their strategy is to appeal to the Canadian taxpayers by telling them that these changes will increase tax savings. Framing their argument in a way that is beneficial to Canadian citizens is allowing their neoliberal argument to be more appealing to the general public. This has enabled the respondents to become the dominant discourse on refugees. The respondents framed the issue in a way that would benefit Canadians when in reality they are doing the opposite, and leaving refugees more susceptible to sickness and disease, making everyone more vulnerable. Their numeric estimates do not account for the fact that the overall cost of health care in Canada has increased in recent years for Canadian citizens as well as for refugees and asylum seekers. All of the respondents' arguments return back to Canadians, money, fairness, etc. while the applicants are more concerned with vulnerability, human rights and equality.

\section{The Court Case Section Three: The Federal Court of Appeal's}

The paper will now look at what Justice MacTavish ended up ruling with regards to each of the arguments that have been discussed in both the respondent and applicant sections as a way of unpacking how she came to her conclusions. It is apparent early on that Justice MacTavish understands the ideological underpinnings of both sides and her decision appears to have the same human rights and humanitarian understanding of this issue as the applicants- namely that is in accordance with the Canadian Charter of Rights and Freedoms, the Canada Health Act, and 
international conventions. When examining the justification for her argument, I found three clear frames that can be used as a lens to unpack her decision. The frames are: 1) Taking Away the Human Dignity of Refugees 2) Against Public Standards of Decency/Cruel and Unusual Treatment 3) Gaps, Inconsistencies, Lack of Evidence. These three frames, and with them, Justice MacTavish's overall argument will be explored below. Due to the fact that Justice MacTavish's argument is in line with the advocates, once again Risk and Information Frames as well as Collective Action Frames can be seen emerging from her overall discourse and discussion.

\section{A) FCA Frame One: Taking Away the Human Dignity of Refugees}

A main issue that Justice MacTavish had with the respondents' argument and justification is that it did not account for human dignity and how refugees are now being forced to give up some of their dignity by making them believe they are not as important as other groups of people. As a result, human dignity was a frame that continuously arose in the case during MacTavish's justification. Furthermore, Justice MacTavish said that "this distinction has an adverse differential effect on refugee claimants from DCO. It puts their lives at risk and perpetuates the stereotypical view that they are cheats and queue jumpers, that their refugee claims are bogus, and that they have come to Canada to abuse the generosity of Canadians. It serves to perpetuate the historical disadvantage suffered by members of an admittedly vulnerable, poor and disadvantaged group" (MacTavish 8-9). Thus, right away MacTavish states that most of the government discourse surrounding refugees and health care is stereotypical and purposely entrenches inequality.

When talking about the argument of cost containment as one of the main objectives of the government when making the 2012 changes, MacTavish argues that "it must also be recognized 
that there are costs associated with forcing people to go onto social assistance in order to access potentially life-saving medications and medical treatment...[and there is] an intangible cost to human dignity that comes with forcing people to quit their jobs and go on welfare in order to access medical care" (MacTavish 72). Justice MacTavish is especially concerned with human dignity as it relates to the respondents' argument that says that charity can be an alternate source for medical care, as this argument does not factor in the cost to human dignity experienced by requiring sick people that are not accustomed to Canadian society to rely on others (MacTavish 73). MacTavish notes that the "Supreme Court of Canada Charter jurisprudence is replete with references to the importance of human dignity [and says that] it is simply demeaning to require desperately ill people to go begging for essential medical treatment” (MacTavish 73). In continuation, MacTavish states that one's access to health care is central to the preservation of human dignity. Forcing people to beg for medical treatment is demeaning and "it sends the message that their lives are worth less than the lives of others. It is cruel and unusual treatment that violates section 12 of the Charter" (MacTavish 169).

Justice MacTavish takes issue with many of the alternative ${ }^{8}$ sources of health care that the respondents have listed that are available to refugee claimants in Canada. One issue is that the alternatives listed are not always timely, which could be detrimental during a medical emergency. In addition they are often uncertain and can cause a lot of extra stress and psychological harm because a person does not know whether or not they are going to get the treatment that they need (MacTavish 75). Another factor hindering the success of refugee claimants from DCO's is the fact that they are not able to receive a work permit until they have been in Canada for 180 days. In addition, refugees that are privately sponsored are not able to go

\footnotetext{
${ }^{8}$ As previously stated, these include provincial/territorial insurance, self-funding, private insurance, and the goodwill of others, including pharmaceutical companies and medical clinics (MacTavish 64).
} 
on social assistance until they have been in Canada for a year (MacTavish 151) Thus, the government is essentially forcing refugees to beg for health care, as these bars make it even harder to access, harming their dignity even further.

When discussing the clear disadvantage of people from DCO countries, and the health care hierarchy that has been created in Canada, Justice MacTavish says that this further marginalizes refugees and strengthens stereotypes that say that refugees from DCO countries are bogus, cheats, and queue jumpers that are trying to take advantage of Canada's generosity (MacTavish 203). Furthermore, she argues that:

this attitude reflects historical stereotypes that have been ascribed to groups of immigrants identified as undesirable ; stereotypes that have their origins in racism, fear of Others, fear of economic competition, and more recently, fears of criminality and terrorism... by limiting the health insurance benefits that are provided to refugee claimants from DCO countries, the executive branch of the Canadian government is perpetuating the stereotypical view that refugee claimants from these countries are undesirable, thereby reinforcing existing prejudice and disadvantage (MacTavish 203).

Thus, the hierarchy that has been created between different categories of refugees has led to increased discrimination and a loss of dignity for refugees who desperately need health care and are forced to either beg people to help them or suffer even more difficulties in the future.

\section{FCA Frame Two: Against Public Standards of Decency/Cruel and Unusual Treatment}

The second frame that Justice MacTavish uses is one that sees this issue as one against public standards of decency by intentionally targeting a vulnerable group in society. Though Justice 
MacTavish ultimately agrees with the applicants' argument, she cannot let their Section 7 Charter claim succeed because they are trying to "impose a positive obligation on the Government of Canada to fund health care for individuals seeking the protection of Canada. The current state of the law in Canada is that section 7 guarantees to life, liberty and security of person do not include a positive right to state funding for health care" (MacTavish 7). That being said, once the Governor in Council decided to provide health insurance coverage to refugee claimants and asylum seekers, they must continue to do so in a non-discriminatory manner and in accordance with the Charter, even though they were originally under no obligation (MacTavish 181) As a result, a large part of MacTavish's argument draws from the fact that the government is not allowed to offer varying levels of coverage for different statuses since this service has been provided since 1957. She also concluded that the OIC's did not breach procedural fairness and they were in fact intra vires with respect to the prerogative powers of the Governor in Council (MacTavish 7).

In Justice MacTavish's opinion:

the decision to change the IFHP was not a neutral decision taken by the Governor in Council that has only incidentally had a negative impact on historically marginalized individuals who were covered under the former IFHP. Rather, the executive branch of government has in this case intentionally targeted an admittedly vulnerable, poor, and disadvantaged group for adverse treatment, making the 2012 changes to the IFHP for the express purpose of inflicting predictable and preventable physical and psychological suffering on many of those seeking the protection of Canada (MacTavish 145). 
It is important to note that she claims that the government has intentionally targeted a group to purposely inflict predictable and preventable suffering for refugee claimants in Canada and is therefore acting irresponsibly. Furthermore, MacTavish does not believe that the issue of 'fairness to Canadians', one of the government's stated objectives, is even an issue, as the cuts do not make health care any more accessible to Canadian citizens. She also argues that the cuts do not address inequality between refugee claimants and Canadians because there was no unfairness in the first place (MacTavish 154). Therefore, Justice MacTavish has concluded that there is:

substantial evidence before [her], not just of philosophical differences with a government policy choice, but of real outrage on the part of informed, affected individuals and groups at what has been done through the 2012 changes to the IFHP... It is a strong indication that the cuts to the IFHP are unacceptable to at least a segment of the Canadian population and do not, in the view of these individuals and organizations, accord with public standards of decency or propriety (MacTavish 158).

With regards to Section 12 of the Charter, MacTavish has decided that "the affected individuals are being subjected to 'treatment' as contemplated by section 12 of the Charter, and that this treatment is indeed "cruel and unusual"" (MacTavish 8). She further argues that "the 2012 modifications to the IFHP potentially jeopardize the health, the safety, and indeed the very lives, of these innocent and vulnerable children in a manner that shocks the conscience and outrages our standards of decency. They violate section 12 of the Charter" (MacTavish 8). Furthermore, Justice MacTavish is especially concerned with the impact of the changes on the children of claimants seeking protection. She argues that: 
to the extent that the 2012 changes to the IFHP were intended to act as a deterrent to so-called 'bogus' claims, it must be recognized that children ordinarily have no choice in where they live; this is a matter that will be determined by the adults in their lives. Children are thus the innocent victims of world events and family choices... some children will only have insurance coverage for conditions that endanger the public health and safety of Canadians, and others will have no insurance coverage whatsoever or any form of health care (MacTavish 158).

Therefore, she states that denying health care to innocent children as a result of the behavior of parents is unjust, illogical and constitutes treatment that is cruel and unusual (MacTavish 165).

Furthermore, regarding the issue of international law and how much influence the CRC and the Convention on the Status of Refugees should have in this case, Justice MacTavish says that she "accept[s] the respondents' contention that because none of the operative portions of the two conventions relied upon by the applicants have been incorporated into Canadian law they do not have the force of law in Canada, nor are they the source of domestic rights or remedies" (MacTavish 118). Though she agrees with the respondents, she also states that the conventions that Canada has signed "are relevant as interpretive guides in a Charter analysis and they will thus be taken into account for that purpose" (MacTavish 118). This means that while a final decision cannot be made as a result of international conventions that Canada has signed, they are still useful as a frame of reference when conducting a Charter analysis, as they are underlined with the importance of human rights.

\section{FCA Frame Three: Gaps, Inconsistencies, Lack of Evidence}

The last frame that was evident throughout the court document was that in general there were gaps, inconsistencies, and a lack of evidence throughout much of the respondents' argument, 
especially with regards to the supposed savings for Canadian taxpayers. For example, Justice MacTavish states that there is "no persuasive evidence to show that the changes to the eligibility and coverage provisions of the IFHP have served to deter unmeritorious claims thereby reducing the cost of the program" (MacTavish 153). The respondents provided information to show that there has been an overall reduction in refugee claims in Canada right after the many changes to the refugee process; however, they did not have enough substantial evidence to show if any of these changes have actually resulted from cuts to the 2012 IFHP. MacTavish therefore states that "it cannot be said that changes were necessary to achieve a legitimate aim" (MacTavish 153). As has been stated in the applicants' argument, MacTavish also questions whether or not the cuts will achieve any savings to Canadian taxpayers, or whether those costs are being downloaded to the provinces and other organizations (MacTavish 15). Furthermore, MacTavish points out that "there is a real cost to Canadian taxpayers in providing these alternative forms of health care" (MacTavish 253) which is the same thing that most of the health care professionals and organizations have concluded as well. The federal government has claimed that they only want to look after spending at the federal level, and are not obligated to look at provincial costs; however one of their stated goals was 'the fairness to Canadian taxpayers'. As a result, "it is not at all clear that Canadian taxpayers are realizing any savings at the end of the day" (MacTavish 255).

In continuation, "the government anticipated saving $\$ 70$ million in the first three years of the new IFHP and \$15 million each year thereafter...while these amounts are substantial, it does not necessarily follow that the anticipated reduction in program spending is entirely, or even primarily attributable to the 2012 changes to the IFHP” (MacTavish 239-240). The respondents have not provided clear enough information to show how these estimates were calculated, or if a 
reduction of DCO claimants were factored in. Another of the government's stated objectives of the changes to the IFHP is that the changes are trying to deter people from coming to Canada. Justice MacTavish argues that "if it were true that there are indeed satisfactory alternatives readily available to those seeking the protection of Canada [from DCO countries], it is difficult to see how changing the IFHP would deter anyone from coming to Canada" (MacTavish 235) which makes the respondents' argument even more contradictory. Justice MacTavish suggests that if claimants from DCO countries are able to receive health care in their home countries (as the government has claimed), "one has to wonder how the availability of health insurance coverage in Canada under the pre-2012 IFHP would have operated as a 'pull factor' in the first place" (MacTavish 166).

Justice MacTavish has concluded that the "changes to the IFHP violate section 15 of the Charter inasmuch as the program now provides a lesser level of health insurance coverage to refugee claimants from DCO countries in comparison to that provided to refugee claimants from non-DCO countries. This distinction is based upon the national origin of the refugee claimants, and does not form part of an ameliorate program" (MacTavish 8). The singling out of claimants from DCO countries means that they are subjected to adverse differential treatment (MacTavish 180).Therefore, Justice MacTavish is focusing her argument on the fact that the new system has created different levels of coverage, making it discriminatory and violating the equality provisions of the Charter. It has been established that there is no positive obligation on the state to provide health care. However, to reiterate, Justice MacTavish states that once the Governor in Council decided to provide health insurance coverage to refugee claimants and asylum seekers in Canada, they must continue to do so in a non-discriminatory manner even though they were initially under no obligation (MacTavish 181). She argues that it is "not open to government to 
enact a law whose policy objectives and provisions single out a disadvantaged group for inferior treatment" (MacTavish 181). Furthermore, Justice MacTavish states that:

the respondents say that there is no such discrimination, as numerous countries have identified as DCO... according to the respondents distinctions made between foreign nationals of diverse origins do not constitute discrimination on the basis of national or ethnic origin...I do not accept this argument. The fact that a program may explicitly exclude Asians, Hispanics and Blacks does not make it any less discriminatory than a program that only excludes Asians (MacTavish 182).

When deciding what countries will be classified as DCO under the Immigration and Refugee Protection Act (IRPA), there is no evidence to suggest that the quality and availability of health care in that country has been factored in. The respondents' argument assumes that refugees from DCO countries can just go home and receive health care, making their refugee claim seem 'bogus' when in reality in most circumstances they are not able to return home, and the health care at home might not be comparable to Canada (MacTavish 197-198).

MacTavish also takes issue with the government's argument that says that: the previous IFHP was perceived by some as constituting a reason why some foreign nationals came to Canada to assert unfounded claims and also a reason why they sought to remain in Canada for as long as possible after their claims were rejected by the IRB and often the Federal Court...there does not, however, appear to have been any attempt by the government to determine whether the subjective perception on the part of certain unidentified individuals ... was in fact justified. Nor has there been any attempt to determine the extent to which, if at all, the availability of state-funded health care operates as a 'pull factor' for non- 
meritorious refugee claimants...there is no persuasive evidence before me to show that the changes to the IFHP have themselves served to deter unmeritorious claims or encourages anyone to leave Canada more quickly (MacTavish 200201).

MacTavish therefore argues that she finds "it troubling that the respondents seek to justify actions that [she] have found to be cruel, inhumane and discriminatory by relying on the subjective perception of unidentified individuals" (MacTavish 232-233). The subjective perception of 'some individuals' is not enough concrete evidence with which to base a decision that negatively affects the availability of health care for an extremely vulnerable population in Canadian society.

MacTavish asks an interesting question- since many claimants from DCO countries do not succeed, "does it necessarily follow that these claims were all bogus brought by queue jumpers and cheats seeking to abuse the generosity of Canadians? To suggest that this is the case is to have a grossly simplistic understanding of the refugee process" (MacTavish 204).

MacTavish concluded that the changes to the IFHP were in fact intra vires as "there is no federal legislation that requires the federal government to provide health care to refugees, refugee claimants, or failed refugee claimants" (MacTavish 100). That being said, the 2012 OIC's can still be subjected to judicial scrutiny, as "the exercise of the Crown prerogative by the Governor in Council is subject to certain limits: it must be intra vires federal jurisdiction, it must be procedurally fair and it must conform to the Charter" (MacTavish 100). Thus, while it was established that there was no duty of procedural fairness owed on the part of the Governor in Council, the OIC's did not conform to the Charter. Her overall judgement concludes that the Orders in Council are inconsistent with the Canadian Charter of Rights and Freedoms, 
specifically sections 12 and 15 that deal with cruel and unusual treatment and discrimination. She ruled that these OIC's are subject to the Charter and as a result of its violation are not in force or effect (MacTavish 266). This judgement is a perfect example of how the courts do not always side with the federal government, and that policy decisions in Canada that do not pass the constitutional test are not acceptable and must be reversed.

\section{B) Wrapping up the Case}

To reiterate, the overall thinking and reasoning behind most of Justice MacTavish's discourse and decisions can be described as a rights based approach that is similar to that of the advocates. While she highlights the importance of international conventions that Canada is a signatory to, she ultimately comes to her conclusion by stating that the changes made to the IFHP are not in accordance with sections 12 and 15 of the Canadian Charter of Rights and Freedoms and are therefore not reasonable in a free and democratic society. Though the government was not originally obligated to provide health care coverage for refugee claimants, once it did in 1957, it had to continue to do so in a way that was consistent with the Charter. Thus, the two main issues that the FCA had with these changes are issues of equality and discrimination, as well as the cruel and unusual treatment of an already vulnerable group, especially as it affects children. Justice MacTavish makes a constitutional argument and views this debate through a legal lens that looks at the Constitution, the Canada Health Act and issues of human dignity, physical and psychological suffering, and public standards of decency.

These frames that I have found can be described once again using the Risk and Information and Collective Action Frames that were discussed in the analysis of the advocates' argument. Justice MacTavish outlines different risks and factual information in the frame section entitled Gaps, Inconsistencies, and Lack of Evidence that shows all of the holes in the 
respondents' argument. Thus, she questioned many of their arguments such as Saving Money for Canadian taxpayers and Ensuring Fairness to Canadians arguing they are not legitimate arguments. MacTavish is also using Collective Action or Injustice Framing by defining an unjust social condition, explaining why it is unjust, discriminatory and against the constitution, and forcing the government to take action to reinstate the previous IFHP with the frames Taking Away the Human Dignity of Refugees and Against Public Standards of Decency/Cruel and

\section{Unusual Treatment.}

Justice MacTavish gave Ottawa four months, until November 4, 2014 to remedy the situation (CBC News Oct. 31, 2014). The federal government has said that four months is not long enough, and decided at the last minute to appeal the Federal Court decision on cuts to the IFHP sparking an uprising from Canada's professional health care community (CARL July 4, 2014). Reinstating federal funding has now become a matter of avoiding contempt of court (The Toronto Star Nov. 5, 2014). Justice Wyman W. Webb of the Federal Court ruled that any inconvenience to the November 4 deadline was "outweighed by the harm that would be suffered by hard-hit refugees. Ottawa's request for stay was denied" (The Toronto Star Nov. 5, 2014). Dr. Philip Berger stated that "the conservative government is recklessly choosing to let vulnerable people, including pregnant women and ill children, suffer rather than accept the very clear and

comprehensive decision of the court" (CARL July 4, 2014). Ultimately, this decision means that refugees will be going many more months without access to health care, remaining at risk even though the Federal Court of Appeal's ruled to reinstate the IFHP (CARL July 4, 2014).

\section{Policy Implications and Recommendations}

I have used a case study approach which has allowed me to examine the four main themes of ideology, equality, accessibility, and the social construction of refugees. I have been 
able to illustrate and identify all of these issues through examination of this court case, which has been a platform that allowed me to explore numerous questions with regard to these themes. The value of approaching this paper through the use of a unique case study is that this approach illuminates and illustrates a huge shift in public policy. It has allowed me to call into question the government's approach to public policy and highlights a significant challenge to the Canadian Charter. In addition, this case study is significant because based on the decision of the Supreme Court of Canada, federal government policy could be overturned, or the decision could allow the government's policy to have effect if the Supreme Court disagrees with Justice MacTavish's ruling. Thus, this case study has allowed me to illustrate government policy and decision making, explain the role of the courts, and illuminate a Charter challenge by stakeholders while going to the center of the debate about refugee rights in Canada, in a free and democratic society.

\section{A) Recommendations with Respect to the Federal Government}

The paper will now look at policy recommendations and the actions that Canada's federal and provincial governments should take moving forward. To begin, since the IFHP falls under federal jurisdiction, it is ultimately the actions of the federal government that will make the greatest impact to change this policy. First and foremost, it is recommended that the federal government repeal the changes to the IFHP and bring in new policy to reflect Justice

MacTavish's ruling. Secondly, the federal government should implement a system that measures and analyzes the implications of these changes. Analysis of the data would be able to inform changes to the policy in the future as well as lead to better health initiatives and opportunities for refugees overall (Barnes 8). The Canadian Healthcare Association has stated that "a health impact assessment of the changes to the IFHP would provide information that could help to clarify the validity of concerns that have been raised and provide a more robust basis for reform 
of refugee health services provision in Canada" (CHA 2). Still, the government has provided no credible statistics, studies, or facts that accurately explain the motives behind their decision (CHA 7). Thus, the third recommendation is that a health impact assessment be performed.

Fourthly, more research, specifically with regards to the government's argument around cost savings needs to be conducted, as professionals mentioned throughout the paper are claiming that this policy change will increase future health care costs. The fifth recommendation for the federal government comes from organizations such as the Canadian Council for Refugees which have argued that there should not be differentiation in the coverage that is provided to refugees based on the category of refugee or the stage of the claimant process that they are in (CCR June 2012). Lastly, the Wellesley Institute has made a list of steps that the federal government needs to make to reverse the 2012 cuts to the IFHP. These steps are to "respond to the cases that have been reported by Canadian Doctors for Refugee Care [and other credible refugee organizations], to convene a roundtable to identify opportunities to collect data more systematically, and respond to the concerns about cuts to the IFHP raised by numerous professional health care associations" (Barnes 12). If the federal government takes these steps Canada is more likely to have a refugee health care program that is acceptable to all parties involved without violation of the Charter. The paper will now look at recommendations for the provinces before moving into joint recommendations.

\section{B) Recommendations with Respect to Provincial Governments}

The first recommendation for provincial governments is the need to develop a standard approach for dealing with uninsured or underinsured refugee patients, including solving administrative complexity that has resulted from these changes (Marwah 13). As such, navigating the confusing healthcare system that only offers coverage for some continues to be a 
challenge for health care professionals. Secondly, Barnes argues that "health care providers also need policies to ensure that refugees and refugee claimants are not denied care... [they] should continue to develop contingency plans, monitor the demand and use of services by refugees, and document the impact of the cuts on individual patients and on provider costs and services" (Barnes 9). This would help ensure that the future health care needs of refugees are understood so that the situation is not exacerbated even further. The costs that provinces and territories are covering in the mean-time through increases in what could have been preventable visits should be tracked so that we can have some data on the impact of these changes. Therefore, the third recommendation is that health authorities can track financial changes by working with medical institutions and providers to collect this information (Barnes 8).

As a way of solving the issue of refugees being afraid of getting deported if they try to access health care, the fourth recommendation for the provinces is that "regional health authorities should implement Access Without Fear policies, where services are provided to immigrants regardless of their immigration status" (Barnes 9). This would be beneficial as more refugees would feel comfortable seeking access to health care. It would also make it easier for health care professionals trying to navigate this confusing health care system. Lastly, the Wellesley Institute has also come up with steps that the provinces and territories should follow to ensure that all refugees are able to access health care. They ask them to:

formally commit to ensuring that refugees no longer supported by IFHP are not denied care, measure and report on the negative health outcomes caused by cuts to the IFHP, track the financial costs of the changes to the IFHP through increases in preventable emergency room visits, and review their existing policies on 
eligibility for provincial/territorial health coverage to ensure that they do not negatively impact immigrant and refugee health (Barnes 12).

Using these guidelines will ensure that refugees in different provinces and territories across Canada are not falling through the cracks and remaining without health care coverage while this decision is being appealed. The paper will now look at joint recommendations for both federal and provincial governments.

\section{C) Joint Federal and Provincial Recommendations}

This section lists a set of recommendations for both provincial and federal governments in Canada. First, though changes have been made in provinces such as Ontario, Quebec, Manitoba, Saskatchewan, Alberta and Nova Scotia, a change in the IFHP policy needs to come from the federal level of government as this issue falls under the federal mandate (Marwah 15). While these provinces are trying to close the gaps and make sure all refugee claimants have access to health care, actions from the federal government will have the largest impact. Though healthcare centers across Canada function at the community level, they are not available across the entire country, which means that their involvement cannot have an impact on all of Canada. Therefore, a second recommendation is that "increasing capacity in community clinics can make a crucial immediate difference to vulnerable populations, but is not, and of itself, a long-term sustainable solution" (Marwah 15). This means that both provincial and federal governments need to work towards solving this policy issue, as community clinics do not have the funding or resources to take on this issue without more help from the federal government.

Third, while the solution to this problem lies in the hands of the federal government, both the provincial and federal governments can do research and use statistics moving forward to 
understand what the actual effects of these changes are. If provincial governments focus on organizing information and statistics about the impacts, they can use this evidence to argue their case that the IFHP should still be in place. The fourth recommendation is that when dealing with the provincial or federal governments, the opinions of health care professionals need to be heard and considered as they are the ones that have direct access to refugees being affected by these changes. Therefore, CIC should "collaborate with service providers and frontline workers to build on what is already working in terms of ensuring health care access to refugee claimants and mitigate the arbitrary and inequitable ways in which IFHP is being administered. This will help to better regularize the status and treatment of all refugees across Canada" (Marwah 15). That being said, this can be quite complicated as there are jurisdictional issues between the provincial and federal governments. Ultimately, there is a need for greater cooperation between the federal government and the provincial governments to ensure that there is consistency in the application of health care coverage, that they are acting in accordance with the FCA ruling, and that they act in concert with respect to future changes.

Though the government has restored temporary coverage while waiting for a date to take this case to the Supreme Court, the temporary program in place that allows for more coverage for children and pregnant women, and removed classifications of refugees is still tiered, with coverage for medications remaining restricted (Levitz January 2015). Furthermore, this temporary program has led to more confusion. Toronto family doctor Ritika Goel stated that "I think many providers don't understand the details of what has happened and therefore are likely to continue to turn people away because they don't have the resources to determine who is covered and who is not for what" (Levitz January 2015). Thus, even though there is temporary coverage in place while this situation gets sorted out in court, refugees are still suffering because 
of all of the confusion that has resulted from these changes. As a result, another policy

recommendation is the call for a clear communication strategy from the federal government to the provincial governments to ensure compliance until the case is appealed to the Supreme Court of Canada.

\section{D) Closing Thoughts on Policy Recommendations}

It is apparent that health services in relation to refugees in Canada are understudied and therefore lack appropriate data to evaluate what the impact on changes to health care policies are, specifically with regards to non-government assisted refugees (CHA 5). Before the cuts to the IFHP there was a lack of information on how changing the IFHP would affect refugees.

Therefore, before attempting to change the IFHP, the government should have studied what the impact of these changes would have resulted in. The fact that the government did not consult with the Canadian Medical Association, Canadian Nurses Association, the Canadian Pharmacists Association and various other healthcare organizations means that they ignored a whole group of professional opinions and as a result did not make a well researched and informed decision about the IFHP. Rather than coming up with a solution that would have been acceptable to both the government as well as health care professionals, the federal government made the cuts that they deemed were necessary and is now being highly criticized. When making policy decisions regarding health care, the government should take the opinions of the health care professionals seriously in order to make the most effective and beneficial decision for all parties involved.

Barnes suggests that a health equity question should be asked before making all policy decisions: "could the proposal have an inequitable impact on some groups and, if so, which groups would be disproportionately affected" (Barnes 3)? This would allow policy makers to mitigate negative effects for vulnerable populations and enhance equity objectives (Barnes 3). 
Justice MacTavish highlights how refugees often do not speak English or French, may have limited formal education and lack familiarity with Canadian culture and values, and that without these skills it is hard to work in Canada upon entrance (MacTavish 68). She says that "to qualify for provincial health insurance, at least in Ontario, a claimant has to have an agreement in place to work full-time for an employer and they must be working under that agreement for six months or longer. Many refugee claimants are only able to access part-time or transitory work that would not allow them to qualify for OHIP benefits" (MacTavish 68). This places them in an extremely vulnerable situation that has now been exacerbated even further by these changes. It is important that refugees and refugee claimants in Canada have a voice in any decision that may have an impact on their health. Though language and cultural barriers might pose a challenge, the government should collaborate with NGOs and other service providers that work with refugees that have been impacted (Barnes 10). It is also important to understand the structural limitations in Canadian society that affect refugees accessing health care, such as the requirement to be working full-time for an extended period of time. This is an expectation that is not possible for refugees who are in ill health, do not speak Canada's official languages, or have issues trying to find a job and enter the labor market as a result of discrimination and xenophobia.

The Canadian Association of Refugee Lawyers stated that "more than 20 national health organizations and every provincial health minister representing various political parties have called on the government to reverse their dangerous cuts" (CARL July 4, 2014). The temporary restoration of coverage will not mark the end of this debate. Immigration Minister Alexander "emphasized that his ministry will continue with its appeal" (The Toronto Star Nov. 5, 2014). Furthermore, he stated that "the government will offer health care to pregnant women, children, and refugee applicants who have convinced a government officer that they would be at risk in 
their home country. Also, the government will give the same level of care regardless of whether an applicant is from a country deemed to be safe or not safe" (Curry Nov. 4, 2014) for the time being. Dr. Rachlis made a powerful statement that really put this debate into perspective. He was quoted saying that "what is certain is that the changes to the IFHP are causing illness, disability and death" (MacTavish 29-29). Thus, the federal government has a responsibility to uphold the Constitution and reinstate the pre-2012 IFHP before the health care situation for refugees in Canada gets any worse.

\section{Directions for Future Research}

This paper could be a good stepping stone for future research. If the appeal ends up going to the Supreme Court of Canada, this paper could be expanded to address what happens in the future with regards to refugee health care in Canada. Furthermore, though it was beyond the scope of this paper, it would be beneficial to include testimonials from refugees that have been personally affected by these changes to provide a more realistic understanding of the impact of these cuts. Since much doubt has been cast as to whether or not the changes have actually been able to save money, or simply download to the costs to others, a study outlining to what extent these changes have actually managed to cut costs would also improve this research. When doing this study, it would also be important to evaluate whether any health care costs that have been saved are actually a result of the IFHP changes, or if the savings are due to the larger overall reforms that the federal government has made to the Canadian refugee determination system.

On a smaller scale, it would be beneficial to look in, depth at the changes that the provinces and territories have implemented since the cuts to see if they are adequately able to fill the gaps in refugee health care insurance, as well as how long they will be able to keep up their efforts. In doing this it is also important to compare what provinces and territories are doing, as a 
way of sharing information so that they may adopt each other's ideas and practices to ensure that refugees have the best care possible. And lastly, if this case does go to the Supreme Court, an

analysis of the frames and discourse used in the ruling would be interesting in comparison to this one to see whether or not the discourses, frames, and overall arguments are similar to what was found in this paper.

\section{Conclusion}

The intention of this paper is to provide a holistic overview of the various perspectives and arguments with regards to the 2012 changes to the Interim Federal Health Program for refugees and asylum seekers in Canada. The paper began by laying out the context and background of refugees, health care and policy in Canada, as well as looking at themes of equality, accessibility, ideology, and the social construction of refugees. These themes continued to reappear throughout the paper as they are central to the refugee health care debate.

Furthermore, the introduction to the Canada Health Act and the Constitution allowed for a better understanding of how Justice MacTavish justified her argument. Using critical discourse and critical frame analysis, this paper sought to outline the dominant frames that have justified the arguments of the applicants, the respondents, and the Federal Court of Appeal's. The frames that I found for each perspective outlined the overall ideological underpinnings that were behind each argument.

The frames that I found for the advocates' argument were 1) Ethical Issues: Changes to the IFHP are seen as unethical 2) Critique of cost saving and 3) Refugees now face increased vulnerability. All of these frames can be understood using a humanitarian lens that says that refugee's human rights and human dignity need to be upheld. The frames that I found for the respondents' argument were 1) Containing financial costs 2) Abuse generosity of 
Canadians/Ensure fairness to citizens and 3) Defend integrity of refugee determination system and deter its abuse. These frames can once again be justified using a neoliberal worldview that is more interested in efficiency than human rights and human dignity. Lastly, the frames that I found for the Federal Court of Appeal's are 1) Taking away the human dignity of refugees 2) Against public standards of decency and cruel and unusual treatment and 3) Gaps, inconsistencies, lack of evidence. These frames are again in line with the advocates' ideology of human rights and humanitarianism and ultimately critique the frames that were found in the respondents' argument. Overall, I find that Canada's current conservative government is using a neoliberal lens to justify their harsh decision-making regarding this issue that disregards human rights; however, it is clear that the humanitarian approach that is used by both the advocates and the FCA is the most popular amongst refugees, academics, health care professionals and many Canadian citizens. This approach is in line with Canadian values of human dignity, equality and fairness. The arguments and frames that have been discussed throughout the paper are seminal to the refugee health care debate. If this case does go to the Supreme Court of Canada, understanding these arguments along with their ideological underpinnings are essential to understanding and having a holistic view of this pressing issue. A date has yet to be set for the hearing to take place. It will be interesting to see what the Supreme Court of Canada rules and how Justice MacTavish's ruling is interpreted, should the Court decide to hear the case. 


\section{Works Cited}

"A Consolidation of The Constitution Acts 1867-1982." Department of Justice Canada (2013): 1-76. Print.

Abu-Laban, Yasmeen, and Judith Garber. "The Construction of the Geography of Immigration as a Policy Problem: The States and Canada Compared." Urban Affairs Review 40.4 (2005): 520-61. Print.

Alexander, Chris. "2014 Annual Report to Parliament on Immigration." Citizenship and Immigration Canada. Government of Canada, 2014. Web.

$<$ http://www.cic.gc.ca/english/resources/publications/annual-report-2014/index.asp\#sec$5-2>$.

Alexander, Chris. "Speaking Notes for Chris Alexander, Canada's Citizenship and Immigration Minister at the News Conference Regarding Canada's Asylum System." Citizenship and Immigration Canada. Government of Canada, 22 Jan. 2014. Web.

"Ameliorate Definition." The Collins English Dictionary. 2015. Web.

<http://www.collinsdictionary.com/dictionary/english/ameliorate>.

"Archived - A Review of the past 12 Months and beyond at Citizenship and Immigration Canada "It's Been a Busy Time, but We Are Not Done Yet," Says Minister Jason Kenney." Citizenship and Immigration Canada. Government of Canada, 24 Aug. 2012. Web.

“Archived- Annual Report to Parliament on Immigration, 2013" Citizenship and Immigration Canada, Government of Canada, 28 Oct. 2013. Web.

"Archived - Reform of the Interim Federal Health Program Ensures Fairness, Protects Public Health and Safety." Citizenship and Immigration Canada. Government of Canada, 25 Apr. 2012. Web.

Arya, Neil, Josephine McMurray, and Meb Rashid. "Enter at Your Own Risk: Government Changes to Comprehensive Care for Newly Arrived Canadian Refugees." Canadian Medical Association Journal 184.17 (2012). Print.

"Asylum-Seekers." UNHCR: The UN Refugee Agency. United Nations High Commissioner for Refugees. Web. <http://www.unhcr.org/pages/49c3646c137.html>.

"Backgrounder: Designated Countries of Origin." Citizenship and Immigration Canada. Government of Canada, 16 Feb. 2012. Web. 23 June 2015.

<http://www.cic.gc.ca/english/department/media/backgrounders/2012/2012-02-16i.asp〉.

Barnes, Steve. "The Real Cost Of Cutting The Interim Federal Health Program.” Wellesley Institute (2013): 1-16. 
Baker, Paul, Costas Gabrielatos, Majid Khosravinik, Michael Krzyzanowski, Tony Mcenery, and Ruth Wodak. "A Useful Methodological Synergy? Combining Critical Discourse Analysis and Corpus Linguistics to Examine Discourses of Refugees and Asylum Seekers in the UK Press." Discourse \& Society 19.3 (2008): 273-306.

Bednarek, Monika, and Helen Caple. "Why Do News Values Matter? Towards a New Methodological Framework for Analyzing News Discourse in Critical Discourse Analysis and Beyond." Discourse \& Society 25.2 (2014): 135-58.

Beiser, Morton. "The Health of Immigrants and Refugees in Canada." Canadian Journal of Public Health 96 (2005): S30 - S44.

Benford, Robert, and David Snow. "Framing Processes and Social Movements: An Overview and Assessment." Annual Review of Sociology 26 (2000): 611-39.

Berg, Bruce, and Howard Lune. "Chapter 11: An Introduction to Content Analysis." Qualitative Research Methods. 08th ed. Pearson, 2012. 349-385. Print

Canadian Association of Refugee Lawyers. "PRESS RELEASE: Federal Court Strikes Down Refugee Health Cuts.” N.p., July 4, 2014. Web. 15 Nov. 2014.

"Canada Health Act." Minister of Justice, 27 Apr. 2015. Web.

"Challenging the Myths: The Truth About Canadian Refugee Law." Canadian Association of Refugee Lawyers (CARL), 2015. Web.

"Changes to the Interim Federal Health Program: Position Statement." Canadian Healthcare Association (2012): 1-9.

"Chapter 1: Introduction: Convention Refugee Definition." Immigration and Refugee Board Canada. 23 June 2015. Web. <http://www.irbcisr.gc.ca/Eng/BoaCom/references/LegJur/Pages/RefDef01.aspx\#n13>.

"Conservative Government Still Undermining Refugee Health Care: Goes behind Closed Doors to Retroactively End IFH Program." Canadian Association of Refugee Lawyers (CARL). 4 Dec. 2014. Web. <http://www.carlacaadr.ca/articles/govtunderminingrefugeehealthcare $>$.

Curry, Bill. "Ottawa to Restore Health Care for Select Refugee Applicants." The Globe and Mail. 4 Nov. 2014. Web. <http://www.theglobeandmail.com/news/politics/ottawa-to-restorehealth-care-for-select-refugee-applicants/article21450700/>. 
Dickson, Robert. George Brian, Beetz, Jean, Estey, Willard Zebedee, McIntyre, William,

Rogers, Lamer, Antonio, Wilson, Bertha. "Between Harbhajan Singh AND The Minister of Employment and Immigration" Supreme Court Judgement Report: [1985] 1 SRC 177. Case Number: 17904 (1985)

Edge, Sara, and Bruce Newbold. "Discrimination and the Health of Immigrants and Refugees: Exploring Canada's Evidence Base and Directions for Future Research in Newcomer Receiving Countries.” J Immigrant Minority Health 15 (2012): 141-146.

Eggerston, Laura. "Health Care Organizations Wait to Talk to Citizenship Minister about Cuts to Refugee Benefits." Canadian Medical Association Journal 187 (2013): 7. Print.

Ellis, Claire. "Constructing Criminals: A Critical Frame Analysis of Canada's Policy Responses to People Smuggling and the Erosion of Refugee Protection." Immigration and Settlement Studies: Major Research Paper (2014): 1-84. Print.

Entman, Robert. "Framing: Toward Clarification of a Fractured Paradigm." Journal of Communication 43.4 (1993): 51-58.

Fitzpatrick, Meagan. "Refugee Health Wrong Priority for Provinces, Kenney Says." CBC News: Politics. 29 June 2012. Web. 24 June 2015. <http://www.cbc.ca/news/politics/refugeehealth-wrong-priority-for-provinces-kenney-says-1.1193757>.

Gale, Peter. "The Refugee Crisis and Fear: Populist Politics and Media Discourse." Journal of Sociology 40.4 (2004): 321-40.

Glauser, Wendy. "Feds Stick with Decision Not to Fund Refugee Health Care.” CMAJ 186.2 (2014): E70.

Goodman, Simon, and Susan Speer. "Category Use in the Construction of Asylum Seekers." Critical Discourse Studies 4.2 (2007): 165-85. Print.

Gordon, Christine. "Are Unaccompanied Alien Children Really Getting a Fair Trial? An Overview of Asylum Law and Children." Denver Journal of International Law and Policy 33.4 (2005): 641-73. Print.

Greschner, Donna. "The Purpose of Canadian Equality Rights." Review of Constitutional Studies 6.2 (2002): 291-323. Print.

Hancock, Trevor. "The Ottawa Charter at 25." Canadian Public Health 102.6 (2011): 404-406.

Hanhan, Dima. "Cuts to Refugee Benefits: CPhA Leads the Fight." Canadian Pharmacists Association. 1 Oct. 2012. Web. <http://www.pharmacists.ca/index.cfm/newsevents/cpha-blog/cuts-to-refugee-benefits-cpha-leads-the-fight/>. 
Hansson, Emily, Tuck, Andrew, Laurie, Steve, and Kwame, McKenzie. "Rates of Mental Illness and Suicidality in Immigrant, Refugee, Ethnocultural, and Racialized Groups in Canada." Canadian Journal of Psychiatry 57.2 (2012): 111-121.

Hardy, Cynthia, and Nelson Phillips. "No Joking Matter: Discursive Struggle in the Canadian Refugee System." Organization Studies 20.1 (1999): 1-24.

"Harper Government Should End Its Attack on Refugees' Health: Editorial." The Toronto Star. 5 Nov. 2014. Web. <http://www.thestar.com/opinion/editorials/2014/11/05/harper_government_should_end_ its_attack_on_refugees_health_editorial.html>.

Hart, Christopher. "Critical Discourse Analysis and Metaphor: Toward a Theoretical Framework." Critical Discourse Studies 5.2 (2008): 91-106.

Hart, Christopher, Betsy Rymes, Mariana Souto-Manning, Cati Brown, and Allan Luke. "Analyzing Political Discourse: Toward a Cognitive Approach." Critical Discourse Studies 2.2 (2005): 189-201.

"Health Care for Refugees." Press Release: Doctors and Lawyers Challenge Federal Health Cuts to Refugees. Canadian Association of Refugee Lawyers (CARL), 25 Feb. 2013. Web. <http://www.carl-acaadr.ca/our-work/issues/IFHP>.

"Health Care System: Canada Health Act." Health Canada. Government of Canada, 2010. Web. <http://www.hc-sc.gc.ca/hcs-sss/medi-assur/cha-lcs/index-eng.php>.

Hilliard, Robert. "An Overview of Immigrants and Refugees in Canada." Canadian Paediatric Society. 1 Dec 2012. Web. http://www.kidsnewtocanada.ca/care/overview.

"Information for University Decision-Makers: Procedural Fairness Guide/Natural Justice and Other Considerations." (2012): 2-9. Queens University. Web.

<http://www.queensu.ca/equity/publications/2013/ProceduralFairnessguideFINAL.pdf>.

"Inside the Charter." The Charter of Rights and Freedoms. 2006. Web. 24 June 2015. $<$ http://www.charterofrights.ca/en/12_00_02>.

Jacoby, William. "Issue Framing and Public Opinion on Government Spending." American Journal of Political Science 44.4 (2000): 750-67. Print.

Karim, H. "Constructions, Deconstructions and Reconstructions: Competing Canadian Discourses on Ethnocultural Terminology." Canadian Journal of Communication 18.2 (1993): 1-16. Print.

Kaufman, Sandra, Michael Elliot, and Deborah Shmueli. "Frames, Framing and Reframing." Conflict Information Consortium, University of Colorado (2003). Beyond Intractability. Web. >. 
Kenney, Jason. "Speaking Notes for The Honourable Jason Kenney, P.C., M.P. Minister of Citizenship, Immigration and Multiculturalism: At a News Conference following the Tabling of Bill C-31, Protecting Canada's Immigration System Act." Citizenship and Immigration Canada. Government of Canada, 16 Feb. 2012. Web.

Kenney, Jason. "Speaking Notes for The Honourable Jason Kenney, P.C., M.P. Minister of Citizenship, Immigration and Multiculturalism: At a News Conference to Announce Royal Assent of the 'Protecting Canada's Immigration System Act'." Citizenship and Immigration Canada. Government of Canada, 29 June 2012. Web.

<http://www.cic.gc.ca/english/department/media/speeches/2012/2012-06-29.asp>.

KhosraviNik, Majid. "The Representation of Refugees, Asylum Seekers and Immigrants in British Newspapers." Journal of Language and Politics 9.1 (2010): 1-28.

Kondro, Wayne. "Limits on Health Care for Refugees.” CMAJ 184.9 (2012): E486-E487.

La Forest, Gérard V. L'Heureux-Dubé, Claire Gonthier, Charles Doherty, Stevenson, William Iacobucci, Frank. "Between: Patrick Francis Ward AND The Attorney General of Canada” Supreme Court Judgement Report: [1993] 2 SCR 689. Case Number: 21937 (1993)

La Forest, Gérard V. L'Heureux-Dubé, Claire Sopinka, John Gonthier, Charles Doherty, Cory Peter deCarteret, Iacobucci, Frank Major, John C. "Between: Kwong Hung Chan AND The Minister of Employment and Immigration" Supreme Court Judgement Report: [1995] 3SCR 593. Case Number: 23813 (1995)

Lacroix, Marie. "Canadian Refugee Policy and the Social Construction of the Refugee Claimant Subjectivity: Understanding Refugeeness." Journal of Refugee Studies 17.2 (2004): 14766. Print.

Levin, Irwin, Sandra Schneider, and Gary Gaeth. "All Frames Are Not Created Equal: A Typology and Critical Analysis of Framing Effects." Organizational Behavior and Human Decision Processes 76.2 (1998): 149-88.

Linton, Lillian, Fred Phelps, Robert Sutherland, John Haggie, Judith Shamian, Jeff Poston, Sandy Buchman, and Andrew Padmos. "Letter to Jason Kenney." Canadian Association of Optometrists, Canadian Association of Social Workers, Canadian Dental Association, Canadian Medical Association, Canadian Nurses Association, Canadian Pharmacists Association, College of Family Physicians of Canada, The Royal Colle. 18 May 2012. Web. <http://www.pharmacists.ca/cpha-ca/assets/File/cpha-on-theissues/SuppBenefitsKenneyEN.pdf $>$.

MacTavish, Justice. "Between: Canadian Doctors for Refugee Care, The Canadian Association of Refugee Lawyers, Daniel Garcia Rodrigues, Hanif Ayubi and Justice for Children and Youth AND Attorney General of Canada and Minister of Citizenship and Immigration." Judgement and Reasons Docket: T-356-13.Citation: 2014 FC 651 (2014). 
Madore, Odette. "The Canada Health Act: Overview and Options." Parliament Information and Research Service (2005): 1-24. Print.

Marwah, Sonal. “Refugee Health Care Cuts In Canada.” Wellesley Institute (2014): 1-17.

Martin, Fiona, and Jennifer Curran. "Separated Children: A Comparison of the Treatment of Separated Child Refugees Entering Australia and Canada." Oxford Journals (2007): 44070. Web.

Mas, Susana. "Chris Alexander Scolds Ontario over Health Care to Refugees." CBC News: Politics. 22 Jan. 2014. Web. <http://www.cbc.ca/news/politics/chris-alexander-scolds-ontarioover-health-care-to-refugees-1.2507008>.

Mildon, Barbara. "Letter from the Canadian Nurses Association." 12 July 2013. Web. <http://cnaaiic.ca/ /media/cna/page-content/pdf fr/letter_to_the_editor_national_post_refugee_health_benefits_e.pdf >.

McGregor, Sue. "Neoliberalism and Health Care.” International Journal of Consumer Studies 25.2 (2001): 82-89.

Payton, Laura. "Federal Government to Appeal Ruling Reversing 'cruel' Cuts to Refugee Health." CBC News: Politics. 4 July 2014. Web. <http://www.cbc.ca/news/politics/federalgovernment-to-appeal-ruling-reversing-cruel-cuts-to-refugee-health-1.2696311>.

Pratt, Anna, and Mariana Valverde. "From Deserving Victims to 'Masters of Confusion' : Redefining Refugees in the 1990s." The Canadian Journal of Sociology 27.2 (2002): 135-61. Print.

"Pre-Removal Risk Assessment." Citizenship and Immigration Canada. Government of Canada, 25 Feb. 2013. Web. <http://www.cic.gc.ca/english/resources/tools/refugees/prra/index.asp>.

Rashid, Dr. Meb, and Dr. Philip Berger. "Let's End the Nasty Fight on Refugee Health Care." Thestar.com. 5 July 2013. Web. <http://www.thestar.com/opinion/commentary/2013/07/05/lets_end_the_nasty_fight_on_ refugee_health_care.html>.

"Refugee Health Cuts: Ottawa Has until Nov. 4 to Put in Place New Policy." CBC News, 31 Oct. 2014 Web. 15 Nov. 2014.< http://www.cbc.ca/news/politics/refugee-health-cuts-ottawahas-until-nov-4-to-put-in-place-new-policy-1.2820485>

Rein, Martin, and Donald Schon. "Frame-Critical Policy Analysis and Frame-Reflective Policy Practice." Knowledge and Policy: The International Journal of Knowledge Transfer and Utilization 9.1 (1996): 85-104.

Sadoway, Geraldine. "Canada's Treatment of Separated Refugee Children." European Journal of Migration and Law 3 (2001): 347-81. Web. 
Sanchez, Lina Maria. "Cuts to the Interim Federal Health Program (IFHP) \& Its Implications on Child \& Youth Refugee Claimants." Justice for Children and Youth. 11 Mar. 2013. Web. $<$ http://jfcy.org/en/blog/cuts-to-the-interim-federal-health-ifh-program-and-itsimplications-on-children-and-youth-refugee-claimants/>.

Shacter, Ron. "The Cases of Chan and Ward." Osgoode Hall Law Journal 35.3/4 (1997): 723-36. Print.

"Standing up for Refugee Health." Canadian Doctors for Refugee Care (CDRC). 4 July 2014. Web. $<$ http://www.doctorsforrefugeecare.ca/>.

Taylor, Dorceta. "The Rise of the Environmental Justice Paradigm: Issue Framing and the Social Construction of Environmental Discourses." American Behavioral Scientist 43.4 (2000): 508-80. Print.

"The Constitution." An Introduction to How Parliament Works. Parliament of Canada, 1982. Web.

"Ultra Vires." Legal Information Institute. Cornell University Law School. Web. $\langle$ https://www.law.cornell.edu/wex/ultra_vires $>$.

United Nations High Commissioner for Refugees. "Convention and Protocol Relating to the Status of Refugees." (1951): 1-52. UNHCR Communications and Public Information Service. Web. <http://www.unhcr.org/3b66c2aa10.html>.

United Nations Human Rights. "Convention on the Rights of the Child." (1989). Office of the High Commissioner for Human Rights. Web.

<http://www.ohchr.org/en/professionalinterest/pages/crc.aspx>

United Nations Human Rights. "Convention Relating to the Status of Refugees." (1951). Office of the High Commissioner for Human Rights. Web.

<http://www.ohchr.org/EN/ProfessionalInterest/Pages/StatusOfRefugees.aspx>

Van Dijk, Teun. "Principles of Critical Discourse Analysis." Discourse \& Society 4.2 (1993): 249-83.

Wrenn, Mary. “Identity, Identity Politics, and Neoliberalism.” PANOECONOMICUS 4 (2014): 503515. 